NBER WORKING PAPER SERIES

COMMUTING, MIGRATION AND LOCAL EMPLOYMENT ELASTICITIES

Ferdinando Monte

Stephen J. Redding

Esteban Rossi-Hansberg

Working Paper 21706

http://www.nber.org/papers/w21706

\author{
NATIONAL BUREAU OF ECONOMIC RESEARCH \\ 1050 Massachusetts Avenue \\ Cambridge, MA 02138 \\ November 2015
}

Much of this research was undertaken while Ferdinando Monte was visiting the International Economics Section (IES) at Princeton. We are grateful to the IES and Princeton more generally for research support. We are also grateful to the editor, four anonymous referees, and conference and seminar participants for helpful comments and suggestions. The views expressed herein are those of the authors and do not necessarily reflect the views of the National Bureau of Economic Research.

NBER working papers are circulated for discussion and comment purposes. They have not been peerreviewed or been subject to the review by the NBER Board of Directors that accompanies official NBER publications.

(C) 2015 by Ferdinando Monte, Stephen J. Redding, and Esteban Rossi-Hansberg. All rights reserved. Short sections of text, not to exceed two paragraphs, may be quoted without explicit permission provided that full credit, including $(\mathcal{C}$ notice, is given to the source. 
Commuting, Migration and Local Employment Elasticities

Ferdinando Monte, Stephen J. Redding, and Esteban Rossi-Hansberg

NBER Working Paper No. 21706

November 2015, Revised November 2016

JEL No. F16,J6,J61,R0

\section{ABSTRACT}

To understand the elasticity of employment to local labor demand shocks, we develop a quantitative general equilibrium model that incorporates spatial linkages in goods markets (trade) and factor markets (commuting and migration). We show that local employment elasticities differ substantially across U.S. counties and commuting zones in ways that are not well explained by standard empirical controls but are captured by commuting measures. We provide independent evidence for these predictions from million dollar plants and find that empirically-observed reductions in commuting costs generate welfare gains of around 3.3 percent and employment reallocations from -20 to 30 percent.

Ferdinando Monte

Georgetown University

McDonough School of Business

37 th \& O Streets, NW

Washington, DC 20057

ferdinando.monte@georgetown.edu

Stephen J. Redding

Department of Economics

and Woodrow Wilson School

Princeton University

Fisher Hall

Princeton, NJ 08544

and NBER

reddings@princeton.edu

\author{
Esteban Rossi-Hansberg \\ Princeton University \\ Department of Economics \\ Fisher Hall \\ Princeton, NJ 08544-1021 \\ and NBER \\ erossi@princeton.edu
}




\title{
Commuting, Migration and Local Employment Elasticities*
}

\author{
Ferdinando Monte ${ }^{\dagger}$ \\ Stephen J. Redding ${ }^{\ddagger}$ \\ Esteban Rossi-Hansberg§ \\ Georgetown University \\ Princeton University \\ Princeton University
}

October 30, 2016

\begin{abstract}
To understand the elasticity of employment to local labor demand shocks, we develop a quantitative general equilibrium model that incorporates spatial linkages in goods markets (trade) and factor markets (commuting and migration). We show that local employment elasticities differ substantially across U.S. counties and commuting zones in ways that are not well explained by standard empirical controls but are captured by commuting measures. We provide independent evidence for these predictions from million dollar plants and find that empirically-observed reductions in commuting costs generate welfare gains of around 3.3 percent and employment reallocations from -20 to 30 percent.
\end{abstract}

JEL CLASSIFICATION: F12, F14, R13, R23

\section{Introduction}

Agents spend about $8 \%$ of their workday commuting to and from work. ${ }^{1}$ They make this significant daily investment, to live and work in different locations, so as to balance their living costs and residential amenities with the wage they can obtain at their place of employment. The ability of firms in a location to attract workers depends, therefore, not only on the ability to attract local residents through migration, but also on the ability to attract commuters from other, nearby, locations. Together, migration and commuting determine the response of local employment to a local labor demand shock, which we term the local employment elasticity. This elasticity is of great policy interest since it determines the impact of local policies, such as transport infrastructure investments, local taxation and regional development programs. Estimating its magnitude has been the subject of a large empirical literature on local labor markets, which

${ }^{*}$ Much of this research was undertaken while Ferdinando Monte was visiting the International Economics Section (IES) at Princeton. We are grateful to the IES and Princeton more generally for research support. We are also grateful to the editor, four anonymous referees, and conference and seminar participants for helpful comments and suggestions.

${ }^{\dagger}$ McDonough School of Business, 37th and O Streets, NW, Washington, DC 20057. ferdinando.monte@georgetown.edu.

${ }_{\ddagger}^{\ddagger}$ Dept. Economics and WWS, Fisher Hall, Princeton, NJ 08544. 609258 4016. reddings@ princeton.edu.

$\S$ Dept. Economics and WWS, Fisher Hall, Princeton, NJ 08544. 609258 4024. erossi@ princeton.edu.

${ }^{1}$ See for example Redding and Turner (2015). 
has considered a variety of sources of local labor demand shocks, including sectoral composition (Bartik shocks), productivity, international trade, natural resource abundance and business cycle fluctuations, as discussed further below. ${ }^{2}$ In this paper we explore the determinants and characteristics of the local employment elasticity (and the corresponding local resident elasticity) using a detailed quantitative spatial equilibrium theory.

We develop a quantitative spatial general equilibrium model that incorporates spatial linkages between locations in both goods markets (trade) and factor markets (commuting and migration). We show that there is no single local employment elasticity. Instead the local employment elasticity is an endogenous variable that differs across locations depending on their linkages to one another in goods and factor markets. Calibrating our model to county-level data for the United States, we find that the elasticity of local employment with respect to local productivity shocks varies from around 0.5 to 2.5 . Therefore an average local employment elasticity estimated from cross-section data can be quite misleading when used to predict the impact of a local shock on any individual county and can lead to substantial under or overprediction of the effect of the shock. We use our quantitative model to understand the systematic determinants of the local employment elasticity and show that a large part of the variation results from differences in commuting links between a location and its neighbors. We then propose variables that can be included in reduced-form regressions to improve their ability to predict the heterogeneity in local employment responses without imposing the full structure of our model.

Our theoretical framework allows for an arbitrary number of locations that can differ in productivity, amenities and geographical relationship to one another. The spatial distribution of economic activity is driven by a tension between productivity differences and home market effects (forces for the concentration of economic activity) and an inelastic supply of land and commuting costs (dispersion forces). Commuting allows workers to access high productivity employment locations without having to live there and hence alleviates the congestion effect in such high productivity locations. We show that the resulting commuting flows between locations exhibit a gravity equation relationship with a much higher distance elasticity than for goods flows, suggesting that moving people is more costly than moving goods across geographic space. We discipline our quantitative spatial model to match the observed gravity equation relationships for trade in goods and commuting flows as well as the observed cross-section distributions of employment, residents and wages across U.S. counties. Given the observed data on wages, employment by workplace, commuting flows and land area, and a parameterization of trade and commuting costs, we show that our model can be used to recover unique values of the unobserved location fundamentals (productivity and amenities) that exactly rationalize the observed data as an equilibrium of the model. We show how the values of these observed variables in an initial equilibrium can be used to undertake counterfactuals for the impact of local labor demand shocks (captured by productivity shocks in our model) and for the impact of changes in trade or commuting costs.

An advantage of our explicitly modeling the spatial linkages between locations is that our framework can be taken to data on local economic activity at different levels of spatial aggregation. In contrast,

\footnotetext{
${ }^{2}$ For a survey of this empirical literature, see Moretti (2011).
} 
existing research that does not explicitly model the spatial linkages between locations is faced with a trade-off when studying local labor markets. On the one hand, larger spatial units have the advantage of reducing the unmodeled spatial linkages between locations. On the other hand, larger spatial units have the disadvantage of reducing the ability to make inferences about local labor markets. Furthermore, there exists no choice of boundaries that eliminates commuting between spatial units. For example, should Princeton, NJ be considered part of New York's or Philadelphia's local labor market? Some of its residents commute to New York, but others commute to Philadelphia. Our approach overcomes these problems by explicitly modeling the geographic linkages between the spatial units. In our baseline specification, we report results for counties, because this is the finest level of geographical detail at which commuting data are reported in the American Community Survey and Decennial Census, and several influential papers in the local labor markets literature have used county data (such as Greenstone, Hornbeck and Moretti, 2010, henceforth GHM, 2010). ${ }^{3}$ In robustness tests, we also report results for commuting zones (CZs), which are aggregations of counties by the U.S. Department of Agriculture designed to minimize commuting flows between locations.

We demonstrate both theoretically and empirically the robustness of our findings of heterogeneous local employment elasticities. From a theoretical perspective, we show that heterogeneous local employment elasticities are not specific to our theoretical model, but rather are a more generic prediction of an entire class of theoretical models consistent with a gravity equation for commuting flows. This prediction holds across a range of different versions of our model, including incorporating heterogeneous land supply elasticities across locations, non-traded goods, congestion in commuting costs, heterogeneity in effective units of labor rather than in amenities, and different assumptions about the ownership of land. These different theoretical specifications can affect the elasticity of wages with respect to productivity, but as long as these specifications yield a gravity equation for commuting flows, they imply the same elasticity of employment with respect to wages. This elasticity can be derived directly from the gravity equation for commuting flows, which we show to be a strong empirical feature of the data.

From an empirical perspective, we show that we continue to find substantial heterogeneity in these local employment elasticities when we incorporate the variable land supply elasticities from Saiz (2010). Introducing this second source of heterogeneity generates more variation in local resident elasticities but does not reduce the variation in local employment elasticities. Furthermore, we continue to find substantial differences between local employment and local residents elasticities, where the only reason that these two elasticities can differ from one another is commuting. We also continue to find substantial heterogeneity in local employment elasticities when we replicate our analysis for CZs rather than counties. The reason is that there are substantial differences across CZs in the extent to which they capture commuting links in a geographic area, and it is these differences that generate the heterogeneity in local employment elasticities.

To provide further evidence of heterogeneous local employment elasticities without using the structure of our model, we use the natural experiment of million dollar plants (MDP) from GHM (2010), one of

\footnotetext{
${ }^{3}$ The LEHD Origin-Destination Employment Statistics (LODES) reports commuting data for more disaggregated spatial units than counties, but there is substantial interpolation, and data are missing for some state-year combinations.
} 
the most influential papers in the local labor markets literature. We compare "winner" and "runner-up" counties that are similar to one another, except that the winner counties were ultimately successful in attracting a MDP. We confirm the findings of a positive average treatment effect of MDPs from GHM (2010). Additionally, we find that this average treatment effect masks considerable heterogeneity across counties, which takes exactly the form predicted by our model. We find that winner counties that are more open in commuting linkages experience substantially and statistically significantly larger increases in employment than other winner counties. ${ }^{4}$ To provide additional independent evidence in support of the mechanism in our model, we also show that changes in net commuting accounted for a substantial proportion of the observed changes in employment from 1990-2010, with substantial heterogeneity across counties in this relative contribution from commuting.

Having established the importance of commuting for local employment responses to local labor demand shocks, we next show that our model provides a platform for evaluating the counterfactual effects of changes in trade and commuting costs. Building on approaches in the international trade literature (e.g. Head and Ries, 2001), we show how observed data on commuting flows over time can be used to back out the empirical distribution of implied changes in commuting costs. We use this empirical distribution to undertake counterfactuals for empirically-plausible changes in commuting costs. For example, reducing commuting costs by the median reduction from 1990-2010 (a reduction of 12 percent), we find an increase in welfare of 3.3 percent. The commuting technology facilitates a separation of workplace and residence, enabling people to work in high productivity locations and live in high amenity locations. Therefore reducing commuting costs increases the concentration of employment in locations that were net importers of commuters in the initial equilibrium (e.g. Manhattan) and enhances the clustering of residents in locations that initially were net exporters of commuters (e.g. parts of New Jersey). This logic seems to suggest that commuting might be important only for larger cities in the U.S., but this is in fact not the case. Although the changes in employment as a result of eliminating commuting are well explained by initial commuting intensity, this intensity cannot be easily proxied for using standard empirical controls, such as land area, size or housing supply elasticities. These results again underscore the relevant information embedded in commuting links.

Our paper is related to several existing literatures. In international trade, our work relates to quantitative models of costly trade in goods following Eaton and Kortum (2002) and extensions. Our research also contributes to the economic geography literature on costly trade in goods and factor mobility, which typically uses variation across regions or systems of cities, including Krugman (1991), Hanson (1996, 2005), Helpman (1998), Fujita et al. (1999), Rossi-Hansberg (2005), Redding and Sturm (2008), Moretti and Klein (2014), Allen and Arkolakis (2014), Caliendo, et al. (2014), Desmet and Rossi-Hansberg (2014) and Redding (2016). Our work also contributes to the urban economics literature on the costly movement of people (commuting), which typically uses variation within cities, including Alonso (1964), Mills (1967), Muth (1969), Lucas and Rossi-Hansberg (2002), Desmet and Rossi-Hansberg (2013), Behrens,

\footnotetext{
${ }^{4}$ These results are consistent with the empirical findings, in another context, of Manning and Petrongolo (2011), which shows that local development policies are fairly ineffective in raising local unemployment outflows, because labor markets overlap, and the associated ripple effects in applications largely dilute the impact of local stimulus across space.
} 
et al. (2014), Ahlfeldt, et al. (2015), Allen, Arkolakis and Li (2015) and Monte (2016). In contrast, we develop a framework in which an arbitrary set of regions are connected in both goods markets (through costly trade) and labor markets (through migration and commuting), and which encompasses both within and across-city interactions. Although incorporating costly goods trade and commuting is a natural idea, our first main contribution is to develop a tractable framework that is amenable to both analytic and quantitative analysis, and for which we provide general results for the existence and uniqueness of the spatial equilibrium. Our second main contribution is to quantify this framework using disaggregated data on trade and commuting for the United States and to show how it provides a platform for evaluating a range of counterfactual interventions. Our third main contribution is to establish the importance of spatial interactions between locations (in particular through commuting) in determining the local economic effects of local labor demand shocks.

Our paper is also related to the large empirical literature on local labor markets, which has estimated the effects of local labor demand shocks: (a) GHM (2010)'s analysis of million dollar plants; (b) Autor, Dorn and Hanson (2013), which examines the local economic effects from the international trade shock provided by China's emergence into global markets; (c) the many empirical studies that use the Bartik (1991) instrument, which interacts aggregate industry shocks with locations' industry employment shares, including Diamond (2016) and Notowidigdo (2013); (d) research on the geographic incidence of macroeconomic shocks, such as the 2008 Financial Crisis and Great Recession, including Mian and Sufi (2014) and Yagan (2016); and (e) work on the impact of natural resource discoveries on the spatial distribution of economic activity, as in Michaels (2011) and Feyrer, Mansur and Sacerdote (2015). ${ }^{5}$ Each of these papers is concerned with evaluating the local impact of economic shocks using data on finely-detailed spatial units. However, these spatial units are typically treated as independent observations in reduced-form regressions, with little attention paid to the linkages between these spatial units in goods and labor markets, and hence with little consideration of the distinction between employment and residents introduced by endogenous commuting decisions. A key contribution of our paper is to show that understanding these spatial linkages is central to evaluating the local impact of these and other economic shocks.

The remainder of the paper is structured as follows. Section 2 develops our theoretical framework. Section 3 discusses the quantification of the model using U.S. data and reports summary statistics on commuting between counties. Section 4 shows both theoretically and empirically the heterogeneity of local employment elasticities. Section 5 studies the effect of changes in commuting costs and Section 6 summarizes our conclusions. A web appendix contains the derivations of theoretical results, the proofs of propositions, additional robustness tests, and a description of the data sources and manipulations.

\footnotetext{
${ }^{5}$ Other related research on local labor demand shocks includes Blanchard and Katz (1992), Bound and Holzer (2000), and Busso, Gregory and Kline (2013).
} 


\section{The Model}

We develop a spatial general equilibrium model in which locations are linked in goods markets through trade and in factor markets through migration and commuting. The economy consists of a set of locations $n, i \in N$. Each location $n$ is endowed with a supply of land $\left(H_{n}\right)$. Following the new economic geography literature, we begin by interpreting land as geographical land area, which is necessarily in perfectly inelastic supply. We later extend our analysis to interpret land as developed land area, which has a positive supply elasticity that we allow to differ across locations. The economy as a whole is populated by a measure $\bar{L}$ of workers, each of whom is endowed with one unit of labor that is supplied inelastically.

\subsection{Preferences and Endowments}

Workers are geographically mobile and have heterogeneous preferences for locations. Each worker chooses a pair of residence and workplace locations to maximize their utility taking as given the choices of other firms and workers. ${ }^{6}$ The preferences of a worker $\omega$ who lives and consumes in location $n$ and works in location $i$ are defined over final goods consumption $\left(C_{n \omega}\right)$, residential land use $\left(H_{n \omega}\right)$, an idiosyncratic amenities shock $\left(b_{n i \omega}\right)$ and commuting costs $\left(\kappa_{n i}\right)$, according to the Cobb-Douglas form, ${ }^{7}$

$$
U_{n i \omega}=\frac{b_{n i \omega}}{\kappa_{n i}}\left(\frac{C_{n \omega}}{\alpha}\right)^{\alpha}\left(\frac{H_{n \omega}}{1-\alpha}\right)^{1-\alpha}
$$

where $\kappa_{n i} \in[1, \infty)$ is an iceberg commuting cost in terms of utility. ${ }^{8}$ The idiosyncratic amenities shock $\left(b_{n i \omega}\right)$ captures the idea that individual workers can have idiosyncratic reasons for living and working in different locations. We model this heterogeneity in amenities following McFadden (1974) and Eaton and Kortum (2002). ${ }^{9}$ For each worker $\omega$ living in location $n$ and working in location $i$, idiosyncratic amenities $\left(b_{n i \omega}\right)$ are drawn from an independent Fréchet distribution,

$$
G_{n i}(b)=e^{-B_{n i} b^{-\epsilon}}, \quad B_{n i}>0, \epsilon>1
$$

where the scale parameter $B_{n i}$ determines the average amenities from living in location $n$ and working in location $i$, and the shape parameter $\epsilon>1$ controls the dispersion of amenities. This idiosyncratic amenities shock implies that different workers make different choices about their workplace and residence locations

\footnotetext{
${ }^{6}$ Throughout the following, we use $n$ to denote a worker's location of residence and consumption and $i$ to denote a worker's location of employment and production, unless otherwise indicated.

${ }^{7}$ For empirical evidence using U.S. data in support of the constant housing expenditure share implied by the Cobb-Douglas functional form, see Davis and Ortalo-Magne (2011).

${ }^{8}$ Although we model commuting costs in terms of utility, they enter the indirect utility function multiplicatively with the wage, which implies that they are proportional to the opportunity cost of time. Therefore, similar results hold if commuting costs are instead modeled as a reduction in effective units of labor, as discussed in Subsection B.15 of the web appendix.

${ }^{9} \mathrm{~A}$ long line of research models location decisions using preference heterogeneity, as in Artuc, Chaudhuri and McClaren (2010), Kennan and Walker (2011), Grogger and Hanson (2011), Moretti (2011) and Busso, Gregory and Kline (2013). Modeling individual heterogeneity in terms of productivity rather than preferences results in a similar specification, as discussed in Section B.14 of the web appendix.
} 
when faced with the same prices and wages. All workers $\omega$ residing in location $n$ and working in location $i$ receive the same wage and make the same consumption and residential land choices. Hence we suppress the implicit dependence on $\omega$ except where important. ${ }^{10}$

To isolate the implications of introducing commuting, we model goods consumption as in the new economic geography literature. The goods consumption index in location $n$ is a constant elasticity of substitution (CES) function of consumption of a continuum of tradable varieties sourced from each location $i$,

$$
C_{n}=\left[\sum_{i \in N} \int_{0}^{M_{i}} c_{n i}(j)^{\rho} d j\right]^{\frac{1}{\rho}}, \quad \sigma=\frac{1}{1-\rho}>1 .
$$

Utility maximization implies that equilibrium consumption in location $n$ of each variety sourced from location $i$ is given by $c_{n i}(j)=\alpha X_{n} P_{n}^{\sigma-1} p_{n i}(j)^{-\sigma}$, where $X_{n}$ is aggregate expenditure in location $n ; P_{n}$ is the price index dual to (3), and $p_{n i}(j)$ is the "cost inclusive of freight" price of a variety produced in location $i$ and consumed in location $n .^{11}$

Utility maximization also implies that a fraction $(1-\alpha)$ of worker income is spent on residential land. We assume that this land is owned by immobile landlords, who receive worker expenditure on residential land as income, and consume only goods where they live. This assumption allows us to incorporate general equilibrium effects from changes in the value of land, without introducing a mechanical externality into workers' location decisions from the local redistribution of land rents. ${ }^{12}$ Using this assumption, total expenditure on consumption goods equals the fraction $\alpha$ of the total income of residents plus the entire income of landlords (which equals the fraction $(1-\alpha)$ of the total income of residents):

$$
P_{n} C_{n}=\alpha \bar{v}_{n} R_{n}+(1-\alpha) \bar{v}_{n} R_{n}=\bar{v}_{n} R_{n}
$$

where $\bar{v}_{n}$ is the average labor income of residents across employment locations; and $R_{n}$ is the measure of residents. Land market clearing determines the land price $\left(Q_{n}\right)$ as a function of the supply of land $\left(H_{n}\right)$ :

$$
Q_{n}=(1-\alpha) \frac{\bar{v}_{n} R_{n}}{H_{n}} .
$$

\footnotetext{
${ }^{10}$ Our baseline specification focuses on a single worker type with a Fréchet distribution of idiosyncratic preferences for tractability, which results in similar choice probabilities to the logit model. In Subsection B.9 of the web appendix, we generalize our analysis to multiple worker types $z$ with different Fréchet scale and shape parameters, which results in similar choice probabilities to the mixed logit model of McFadden and Train (2000).

${ }^{11}$ In Subsection B.11 of the web appendix, we show how this standard specification can be further generalized to introduce non-traded consumption goods.

${ }^{12}$ In Subsection B.12 of the web appendix, we show that the model has similar properties if landlords consume both consumption goods and residential land, although expressions are less elegant. In the web appendix, we also report the results of a robustness test, in which we instead assume that land is partially owned locally and partially owned by a national portfolio that redistributes land rents to workers throughout the economy (as in Caliendo et al. 2014).
} 


\subsection{Production}

Again to isolate the implications of introducing commuting, we also model production as in the new economic geography literature. Tradeable varieties are produced using labor under monopolistic competition and increasing returns to scale. To produce a variety, a firm must incur a fixed cost of $F$ and a constant variable cost that depends on a location's productivity $A_{i} \cdot{ }^{13}$ Therefore the total amount of labor $\left(l_{i}(j)\right)$ required to produce $x_{i}(j)$ units of a variety $j$ in location $i$ is $l_{i}(j)=F+x_{i}(j) / A_{i}{ }^{14}$

Profit maximization implies that equilibrium prices are a constant mark-up over marginal cost: $p_{n i}(j)=$ $\left(\frac{\sigma}{\sigma-1}\right) \frac{d_{n i} w_{i}}{A_{i}}$, where $w_{i}$ is the wage in location $i$. Combining profit maximization and zero profits, equilibrium output of each variety is equal to a constant: $x_{i}(j)=A_{i} F(\sigma-1)$. This constant equilibrium output of each variety and labor market clearing together imply that the total measure of produced varieties $\left(M_{i}\right)$ is proportional to the measure of employed workers $\left(L_{i}\right)$,

$$
M_{i}=\frac{L_{i}}{\sigma F}
$$

\subsection{Goods Trade}

The model implies a gravity equation for bilateral trade between locations. Using the CES expenditure function, the equilibrium pricing rule, and the measure of firms in (6), the share of location $n$ 's expenditure on goods produced in location $i$ is

$$
\pi_{n i}=\frac{M_{i} p_{n i}^{1-\sigma}}{\sum_{k \in N} M_{k} p_{n k}^{1-\sigma}}=\frac{L_{i}\left(d_{n i} w_{i} / A_{i}\right)^{1-\sigma}}{\sum_{k \in N} L_{k}\left(d_{n k} w_{k} / A_{k}\right)^{1-\sigma}} .
$$

Therefore trade between locations $n$ and $i$ depends on bilateral trade costs $\left(d_{n i}\right)$ in the numerator ("bilateral resistance") and on trade costs to all possible sources of supply $k$ in the denominator ("multilateral resistance"). Equating revenue and expenditure, and using zero profits, workplace income in each location equals total expenditure on goods produced in that location, namely, ${ }^{15}$

$$
w_{i} L_{i}=\sum_{n \in N} \pi_{n i} \bar{v}_{n} R_{n}
$$

\footnotetext{
${ }^{13}$ We assume a representative firm within each location. However, it is straightforward to generalize the analysis to introduce firm heterogeneity with an untruncated Pareto productivity distribution following Melitz (2003).

${ }^{14}$ In Subsection B.13 of the web appendix, we generalize the production technology to include intermediate inputs (as in Krugman and Venables 1995 and Eaton and Kortum 2002), commercial land use and physical capital. As heterogeneous local employment elasticities are a generic prediction of gravity in commuting, they also hold under this production structure.

${ }^{15}$ Although a location's total workplace income equals total expenditure on the goods that it produces, total residential income can differ from total workplace income (because of commuting). Therefore total workplace income need not equal total residential expenditure, which implies that total exports need not equal total imports. When we take the model to the data, we also allow total residential expenditure to differ from total residential income, which provides another reason for trade deficits. Within the model, these two variables can diverge if landlords own land in different locations from where they consume. This is how we interpret trade deficits in the empirical section.
} 
Using the equilibrium pricing rule and labor market clearing (6), the price index dual to the consumption index (3) can be expressed as

$$
P_{n}=\frac{\sigma}{\sigma-1}\left(\frac{1}{\sigma F}\right)^{\frac{1}{1-\sigma}}\left[\sum_{i \in N} L_{i}\left(d_{n i} w_{i} / A_{i}\right)^{1-\sigma}\right]^{\frac{1}{1-\sigma}}=\frac{\sigma}{\sigma-1}\left(\frac{L_{n}}{\sigma F \pi_{n n}}\right)^{\frac{1}{1-\sigma}} \frac{d_{n n} w_{n}}{A_{n}}
$$

where the second equality uses (7) to write the price index (9) as in the class of models considered by Arkolakis, Costinot and Rodriguez-Clare (2012) and Allen, Arkolakis and Takahashi (2014).

\subsection{Labor Mobility and Commuting}

Workers are geographically mobile and choose their pair of residence and workplace locations to maximize their utility. Given our specification of preferences (1), the indirect utility function for a worker $\omega$ residing in location $n$ and working in location $i$ is

$$
U_{n i \omega}=\frac{b_{n i \omega} w_{i}}{\kappa_{n i} P_{n}^{\alpha} Q_{n}^{1-\alpha}}
$$

Indirect utility is a monotonic function of idiosyncratic amenities $\left(b_{n i \omega}\right)$ and these amenities have a Fréchet distribution. Therefore, the indirect utility for a worker living in location $n$ and working in location $i$ also has a Fréchet distribution: $G_{n i}(U)=e^{-\Psi_{n i} U^{-\epsilon}}$, where $\Psi_{n i}=B_{n i}\left(\kappa_{n i} P_{n}^{\alpha} Q_{n}^{1-\alpha}\right)^{-\epsilon} w_{i}^{\epsilon}$. Each worker selects the bilateral commute that offers her the maximum utility, where the maximum of Fréchet distributed random variables is itself Fréchet distributed. Using these distributions of utility, the probability that a worker chooses to live in location $n$ and work in location $i$ is

$$
\lambda_{n i}=\frac{B_{n i}\left(\kappa_{n i} P_{n}^{\alpha} Q_{n}^{1-\alpha}\right)^{-\epsilon} w_{i}^{\epsilon}}{\sum_{r \in N} \sum_{s \in N} B_{r s}\left(\kappa_{r s} P_{r}^{\alpha} Q_{r}^{1-\alpha}\right)^{-\epsilon} w_{s}^{\epsilon}} \equiv \frac{\Phi_{n i}}{\Phi} .
$$

Therefore the idiosyncratic shock to preferences $b_{n i \omega}$ implies that individual workers choose different bilateral commutes when faced with the same prices $\left(P_{n}, Q_{n}, w_{i}\right)$, commuting costs $\left(\kappa_{n i}\right)$ and location characteristics $\left(B_{n i}\right)$. Other things equal, workers are more likely to live in location $n$ and work in location $i$, the lower the consumption goods price index $\left(P_{n}\right)$ and land prices $\left(Q_{n}\right)$ in $n$, the higher the wages $\left(w_{i}\right)$ in $i$, the more attractive average amenities $\left(B_{n i}\right)$, and the lower the commuting costs $\left(\kappa_{n i}\right)$.

Summing these probabilities across workplaces $i$ for a given residence $n$, we obtain the overall probability that a worker resides in location $n\left(\lambda_{R n}\right)$. Similarly, summing across residences $n$ for a given workplace $i$, we obtain the overall probability that a worker works in location $i\left(\lambda_{L i}\right)$. So,

$$
\lambda_{R n}=\frac{R_{n}}{\bar{L}}=\sum_{i \in N} \lambda_{n i}=\sum_{i \in N} \frac{\Phi_{n i}}{\Phi}, \quad \text { and } \quad \lambda_{L i}=\frac{L_{n}}{\bar{L}}=\sum_{n \in N} \lambda_{n i}=\sum_{n \in N} \frac{\Phi_{n i}}{\Phi},
$$

where national labor market clearing corresponds to $\sum_{n} \lambda_{R n}=\sum_{i} \lambda_{L i}=1$.

The average income of a worker living in $n$ depends on the wages in all the nearby employment 
locations. To construct this average income of residents, note first that the probability that a worker commutes to location $i$ conditional on living in location $n$ is

$$
\lambda_{n i \mid n}=\frac{B_{n i}\left(w_{i} / \kappa_{n i}\right)^{\epsilon}}{\sum_{s \in N} B_{n s}\left(w_{s} / \kappa_{n s}\right)^{\epsilon}}
$$

Equation (13) implies a commuting gravity equation, with an elasticity of commuting flows with respect to commuting costs $\left(\kappa_{n i}\right)$ of $-\epsilon$. Therefore, the probability of commuting to location $i$ conditional on living in location $n$ depends on the wage $\left(w_{i}\right)$, amenities $\left(B_{n i}\right)$ and commuting costs $\left(\kappa_{n i}\right)$ for workplace $i$ in the numerator ("bilateral resistance"), as well as the wage $\left(w_{s}\right)$, amenities $\left(B_{n s}\right)$ and commuting costs $\left(\kappa_{n s}\right)$ for all other possible workplaces $s$ in the denominator ("multilateral resistance"). This gravity equation prediction is consistent with the existing empirical literature on commuting and migration, including McFadden (1974), Grogger and Hanson (2011) and Kennan and Walker (2011). In Subsection B.8 of the web appendix, we show that heterogeneous local employment elasticities are a generic prediction of the class of models consistent with a gravity equation for commuting flows.

Using these conditional commuting probabilities, we obtain the following labor market clearing condition that equates the measure of workers employed in location $i\left(L_{i}\right)$ with the measure of workers choosing to commute to location $i$, namely,

$$
L_{i}=\sum_{n \in N} \lambda_{n i \mid n} R_{n}
$$

where $R_{n}$ is the measure of residents in location $n$. Expected worker income conditional on living in location $n$ is then equal to the wages in all possible workplaces weighted by the probabilities of commuting to those workplaces conditional on living in $n$, or

$$
\bar{v}_{n}=\sum_{i \in N} \lambda_{n i \mid n} w_{i}
$$

Hence expected worker income $\left(\bar{v}_{n}\right)$ is high in locations that have low commuting costs (low $\left.\kappa_{n i}\right)$ to highwage employment locations. ${ }^{16}$

Finally, population mobility implies that expected utility is the same for all pairs of residence and workplace and equal to expected utility for the economy as a whole. That is,

$$
\bar{U}=\mathbb{E}\left[U_{n i \omega}\right]=\Gamma\left(\frac{\epsilon-1}{\epsilon}\right)\left[\sum_{r \in N} \sum_{s \in N} B_{r s}\left(\kappa_{r s} P_{r}^{\alpha} Q_{r}^{1-\alpha}\right)^{-\epsilon} w_{s}^{\epsilon}\right]^{\frac{1}{\epsilon}} \text { all } n, i \in N
$$

where $\mathbb{E}$ is the expectations operator and the expectation is taken over the distribution for the idiosyncratic component of utility and $\Gamma(\cdot)$ is the Gamma function.

Although expected utility is equalized across all pairs of residence and workplace, real wages differ as a result of preference heterogeneity. Workplaces and residences face upward-sloping supply functions for

\footnotetext{
${ }^{16}$ We treat agents and workers as synonymous, which abstracts from a labor force participation decision, and enables us to isolate the implications of introducing commuting into the standard new economic geography model.
} 
workers and residents respectively (the choice probabilities (12)). Each workplace must pay higher wages to increase commuters' real income and attract additional workers with lower idiosyncratic amenities for that workplace. Similarly, each residential location must offer a lower cost of living to increase commuters' real income and attract additional residents with lower idiosyncratic amenities for that residence. Bilateral commutes with attractive characteristics (high workplace wages and low residence cost of living) attract additional commuters with lower idiosyncratic amenities, until expected utility (taking into account idiosyncratic amenities) is the same across all bilateral commutes.

\subsection{General Equilibrium}

The general equilibrium of the model can be referenced by the following vector of six variables $\left\{w_{n}\right.$, $\left.\bar{v}_{n}, Q_{n}, L_{n}, R_{n}, P_{n}\right\}_{n=1}^{N}$ and a scalar $\bar{U}$. Given this equilibrium vector and scalar, all other endogenous variables of the model can be determined. This equilibrium vector solves the following six sets of equations: income equals expenditure (8), average residential income (15), land market clearing (5), workplace choice probabilities ((12) for $\left.L_{n}\right)$, residence choice probabilities ((12) for $\left.R_{n}\right)$, and price indices (9). The last condition needed to determine the scalar $\bar{U}$ is the labor market clearing condition, $\bar{L}=\sum_{n \in N} R_{n}=\sum_{n \in N} L_{n}$.

Proposition 1 (Existence and Uniqueness) If $1+\epsilon<\sigma(1+(1-\alpha) \epsilon)$ there exists a unique general equilibrium of this economy.

All the proofs of propositions are contained in the web appendix. This condition for the existence of a unique general equilibrium in Proposition 1 is a generalization of the condition in the Helpman (1998) model to incorporate commuting and heterogeneity in worker preferences over locations. Defining $\tilde{\alpha}=\alpha /(1+1 / \epsilon)$, this condition for a unique general equilibrium can be written as $\sigma(1-\tilde{\alpha})>1$. Assuming prohibitive commuting costs $\left(\kappa_{n i} \rightarrow \infty\right.$ for $\left.n \neq i\right)$ and taking the limit of no heterogeneity in worker preference over locations $(\epsilon \rightarrow \infty)$, this reduces to the Helpman (1998) condition for a unique general equilibrium of $\sigma(1-\alpha)>1$.

We follow the new economic geography literature in modeling agglomeration forces through love of variety and increasing returns to scale. But the system of equations for general equilibrium in our new economic geography model is isomorphic to a version of Eaton and Kortum (2002) and Redding (2016) with commuting and external economies of scale or a version of Armington (1969) with commuting and external economies of scale (as in Allen and Arkolakis 2014 and Allen, Arkolakis and Li 2015), as summarized in the following proposition.

Proposition 2 (Isomorphisms) The system of equations for general equilibrium in our new economic geography model with commuting and agglomeration forces through love of variety and increasing returns to scale is isomorphic to that in a version of the Eaton and Kortum (2002) model with commuting and external economies of scale or that in a version of the Armington (1969) model with commuting and external economies of scale. 


\subsection{Computing Counterfactuals}

We use our quantitative framework to solve for the counterfactual effects of changes in the exogenous variables of the model (productivity $A_{n}$, amenities $B_{n i}$, commuting costs $\kappa_{n i}$, and trade costs $d_{n i}$ ) without having to necessarily determine the unobserved values of these exogenous variables. Instead, in the web appendix, we show that the system of equations for the counterfactual changes in the endogenous variables of the model can be written solely in terms of the observed values of variables in an initial equilibrium (employment $L_{i}$, residents $R_{i}$, workplace wages $w_{n}$, average residential income $\bar{v}_{n}$, trade shares $\pi_{n i}$, and commuting probabilities $\lambda_{n i}$ ). This approach uses observed bilateral commuting probabilities to capture unobserved bilateral commuting costs and amenities. Similarly, if bilateral trade shares between locations are available, they can be used to capture unobserved bilateral trade frictions (as in Dekle, Eaton and Kortum 2007). However, since bilateral trade data are only available at a higher level of aggregation than the counties we consider in our data, we make some additional parametric assumptions to solve for implied bilateral trade shares between counties, as discussed below. Throughout this theoretical section, we assume for simplicity that trade is balanced, so that income equals expenditure. However, when taking the model to the data, we allow for intertemporal trade deficits that are treated as exogenous in our counterfactuals, as in Dekle, Eaton and Kortum (2007) and Caliendo and Parro (2015), as discussed further below.

\section{Data and Measurement}

Our empirical analysis combines data from a number of different sources for the United States. From the Commodity Flow Survey (CFS), we use data on bilateral trade and distances shipped for 123 CFS regions. Data on commuting probabilities between counties come from the American Community Survey (ACS) 2006-10 and U.S. Census 1990. From the Bureau of Economic Analysis (BEA), we use data on employment and wages by workplace. We combine these data sources with a variety of other Geographical Information Systems (GIS) data. We use our data on employment and commuting to calculate the implied number of residents and their average income by county. First, from commuter market clearing (14), we obtain the number of residents $\left(R_{n}\right)$ using data on the number of workers $\left(L_{n}\right)$ and commuting probabilities conditional on living in each location $\left(\lambda_{n i \mid n}\right)$. Second, we use these conditional commuting probabilities, together with county wages, to obtain average residential income $\left(\bar{v}_{n}\right)$ as defined in equation (15).

\subsection{Gravity in Goods Trade}

In the Commodity Flow Survey (CFS) data, we observe bilateral trade flows and distances shipped between 123 CFS regions and trade deficits for each these CFS regions. ${ }^{17}$ To quantify the model at the county level, we allocate the deficit for each CFS region across the counties within that region according to their shares

\footnotetext{
${ }^{17}$ Other recent studies using the CFS data include Caliendo et. al (2014), Duranton, Morrow and Turner (2014) and Dingel (2015). The CFS is a random sample of plant shipments within the United States (foreign trade shipments are not included). CFS regions are the smallest geographical units for which this random sample is representative, which precludes constructing bilateral trade flows between smaller geographical units using the sampled shipments.
} 
of CFS residential income (as measured by $\left.\bar{v}_{i} R_{i}\right)$. Using the resulting trade deficits for each county $\left(D_{i}\right)$, we solve the equality between income and expenditure (8) for unobserved county productivities $\left(A_{i}\right)$ :

$$
w_{i} L_{i}-\sum_{n \in N} \frac{L_{i}\left(d_{n i} w_{i} / A_{i}\right)^{1-\sigma}}{\sum_{k \in N} L_{k}\left(d_{n k} w_{k} / A_{k}\right)^{1-\sigma}}\left[\bar{v}_{n} R_{n}+D_{n}\right]=0
$$

where we observe (or have solved for) wages $\left(w_{i}\right)$, employment $\left(L_{i}\right)$, average residential income $\left(\bar{v}_{i}\right)$, residents $\left(R_{i}\right)$ and trade deficits $\left(D_{i}\right)$.

Given the elasticity of substitution $(\sigma)$, our measures for $\left(w_{i}, L_{i}, \bar{v}_{i}, R_{i}, D_{i}\right)$ and a parameterization of trade costs $\left(d_{n i}^{1-\sigma}\right)$, equation (17) provides a system of $N$ equations that can be solved for a unique vector of $N$ unobserved productivities $\left(A_{i}\right)$. We prove this formally in the next proposition.

Proposition 3 (Productivity Inversion) Given the elasticity of substitution ( $\sigma$ ), our measures of wages, employment, average residential income, residents and trade deficits $\left\{w_{i}, L_{i}, \bar{v}_{i}, R_{i}, D_{i}\right\}$, and a parameterization of trade costs $\left(d_{n i}^{1-\sigma}\right)$, there exist unique values of the unobserved productivities $\left(A_{i}\right)$ for each location $i$ that are consistent with the data being an equilibrium of the model.

The resulting solutions for productivities $\left(A_{i}\right)$ capture characteristics (e.g. natural resources) that make a location more or less attractive for employment conditional on the observed data and the parameterized values of trade costs. These characteristics include access to international markets. To the extent that such international market access raises employment $\left(L_{i}\right)$, and international trade flows are not captured in the CFS, this will be reflected in the model in higher productivity $\left(A_{i}\right)$ to rationalize the higher observed employment. ${ }^{18}$ Having recovered these unique unobserved productivities $\left(A_{i}\right)$, we can solve for the implied bilateral trade flows between counties $\left(X_{n i}\right)$ using equation (7) and $X_{n i}=\pi_{n i} \bar{v}_{n} R_{n}$. We use these solutions for bilateral trade between counties in our counterfactuals for changes in the model's exogenous variables, as discussed above.

To parameterize trade costs $\left(d_{n i}^{1-\sigma}\right)$, we assume a central value for the elasticity of substitution between varieties from the existing empirical literature of $\sigma=4$, which is in line with the estimates of this parameter using price and expenditure data in Broda and Weinstein (2006). ${ }^{19}$ We model bilateral trade costs $\left(d_{n i}\right)$ as a function of distance. For bilateral pairs with positive trade, we assume that bilateral trade costs are a constant elasticity function of distance and a stochastic error $\left(d_{n i}=d i s t_{n i}^{\psi} \tilde{e}_{n i}\right)$. For bilateral pairs with zero trade, the model implies prohibitive trade costs $\left(d_{n i} \rightarrow \infty\right){ }^{20}$ Taking logarithms in the trade share

\footnotetext{
${ }^{18}$ We find that measured productivity $\left(A_{i}\right)$ is correlated with observable proxies for productivity, such as access to natural water. Regressing $\log A_{i}$ on a dummy indicating if a county is in the $10 \%$ of counties closest to the ocean or a navigable river we find a positive and statistically significant estimated coefficient (standard error) of $0.21(0.02)$ for the ocean and 0.04 (0.02) for a navigable river. The data on distances are from Rappaport and Sachs (2003).

${ }^{19}$ This assumed value implies an elasticity of trade with respect to trade costs of $-(\sigma-1)=3$, which is close to the central estimate of this parameter of 4.12 in Simonovska and Waugh (2014).

${ }^{20}$ One interpretation is that trade requires prior investments in transport infrastructure that are not modeled here. For bilateral pairs for which these investments have been made, trade can occur subject to finite costs. For other bilateral pairs for which they have not been made, trade is prohibitively costly. We adopt our specification for tractability, but other rationalizations for zero trade flows include non-CES preferences or granularity.
} 


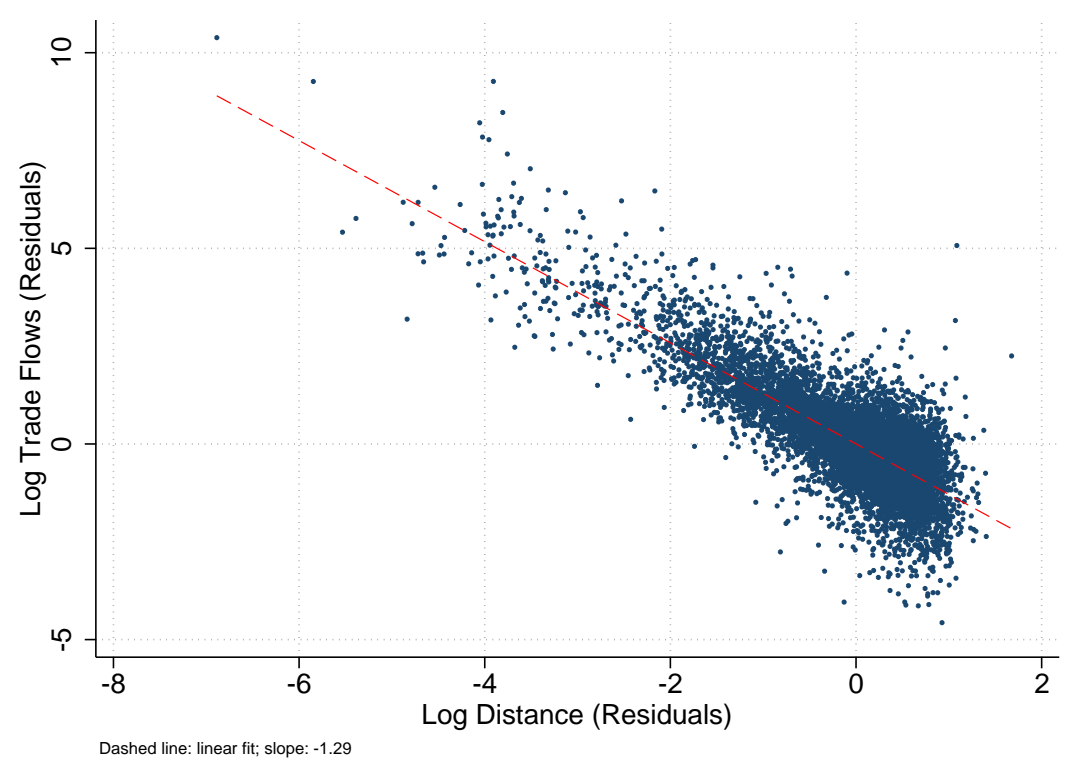

Figure 1: Gravity in Goods Trade Between CFS Regions

(7) for pairs with positive trade, the value of bilateral trade between source $i$ and destination $n\left(X_{n i}\right)$ can be expressed as

$$
\log X_{n i}=\zeta_{n}+\chi_{i}-(\sigma-1) \psi \log d i s t_{n i}+\log e_{n i},
$$

where the source fixed effect $\left(\chi_{i}\right)$ controls for employment, wages and productivity $\left(L_{i}, w_{i}, A_{i}\right)$; the destination fixed effect $\left(\zeta_{n}\right)$ controls for average income, $\bar{v}_{n}$, residents, $R_{n}$, and multilateral resistance (as captured in the denominator of equation (7)); and $\log e_{n i}=(1-\sigma) \log \tilde{e}_{n i}$.

Estimating the gravity equation (18) for all bilateral pairs with positive trade using OLS, we find a regression R-squared of 0.83. In Figure 1, we display the conditional relationship between the log value of trade and log distance, after removing source and destination fixed effects from both log trade and log distance. Consistent with the existing empirical trade literature, we find that the log linear functional form provides a good approximation to the data, with a tight and approximately linear relationship between the two variables. We estimate a coefficient on $\log$ distance of $-(\sigma-1) \psi=-1.29$. For our assumed value of $\sigma=4$, this implies an elasticity of trade costs with respect to distance of $\psi=0.43$. The tight linear relationship in Figure 1, makes us confident in this parametrization of trade costs as $d_{n i}^{1-\sigma}=d i s t_{n i}^{-1.29}$ as a way of using equation (17) to solve for unobserved productivities $\left(A_{i}\right)$.

To provide an alternative check on our specification, we aggregate the model's predictions for trade between counties within pairs of CFS regions, and compare these predictions to the data in Figure 2. The only way in which we used the data on trade between CFS regions was to estimate the distance elasticity $-(\sigma-1) \psi=-1.29$. Given this distance elasticity, we use the goods market clearing condition (17) to solve for productivities and generate predictions for bilateral trade between counties and hence CFS regions, as discussed above. Therefore, the model's predictions and the data can differ from one another. Nonetheless, we find a strong and approximately log linear relationship between the model's predictions and the data, which is tighter for the larger trade values that account for most of aggregate trade. 


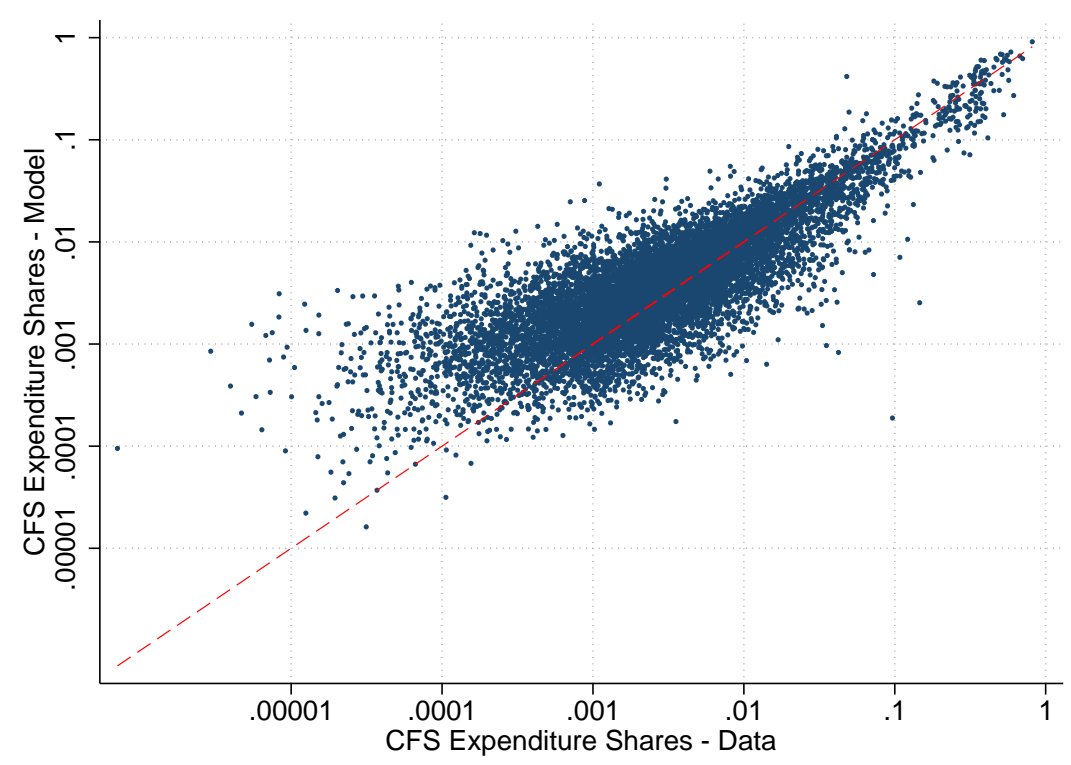

Figure 2: Bilateral Trade Shares in the Model and Data

\subsection{The Magnitude and Gravity of Commuting Flows}

We start by providing evidence on the quantitative relevance of commuting as a source of spatial linkages between counties and CZ's. To do so, we use data from the American Community Survey (ACS), which reports county-to-county worker flows for 2006-2010. To abstract from business trips that are not between a worker's usual place of residence and workplace, we define commuting flows as those of less than 120 kilometers in each direction (a round trip of 240 kilometers). ${ }^{21}$

In Table 1, we report some descriptive statistics for these commuting flows. We find that commuting beyond county boundaries is substantial and varies in importance across locations. For the median county, around 27 percent of its residents work outside the county (first row, fifth column) and around 20 percent of its workers live outside the county (second row, fifth column). For the county at the 90th percentile, these two figures rise to 53 and 37 percent respectively (seventh column, first and second rows respectively). Consequently, we find substantial dispersion across counties in the ratio of employment to residents $\left(L_{i} / R_{i}\right)$, which captures the extent to which a county is an importer of commuters $\left(L_{i} / R_{i}<1\right)$ or an exporter of commuters $\left(L_{i} / R_{i}>1\right)$. This ratio ranges from 0.67 at the 10th percentile to 1.11 at the 90th percentile (third row, columns three and seven respectively). In Subsection C.1 of the web appendix, we show that this commuting measure is not only heterogeneous across counties, but is also hard to explain with standard empirical controls, such as land area, size or supply elasticities for developed land.

One might think that using commuting zones $(\mathrm{CZs})$ circumvents the need to incorporate commuting into the analysis, since the boundaries of these areas are drawn to minimize commuting flows. Nevertheless, we find that CZ's provide an imperfect measure of local labor markets, with substantial commuting

\footnotetext{
${ }^{21}$ The majority of commutes are less than 45 minutes in each direction (Duranton and Turner 2011). In our analysis, we measure distance between counties' centroids. We choose the 120 kilometers threshold based on a change in slope of the relationship between log commuters and log distance at this distance threshold. See the web appendix for further discussion.
} 


\begin{tabular}{|c|c|c|c|c|c|c|c|c|c|c|}
\hline & Min & p5 & $\mathrm{p} 10$ & $\mathrm{p} 25$ & p50 & p75 & p90 & p95 & Max & Mean \\
\hline Commuters from Residence & 0.00 & 0.03 & 0.06 & 0.14 & 0.27 & 0.42 & 0.53 & 0.59 & 0.82 & 0.29 \\
\hline Commuters to Workplace & 0.00 & 0.03 & 0.07 & 0.14 & 0.20 & 0.28 & 0.37 & 0.43 & 0.81 & 0.22 \\
\hline Employment/Residents & 0.26 & 0.60 & 0.67 & 0.79 & 0.92 & 1.02 & 1.11 & 1.18 & 3.88 & 0.91 \\
\hline Outside CZ — Total (Res) & 0.00 & 0.02 & 0.04 & 0.14 & 0.33 & 0.58 & 0.79 & 0.89 & 1.00 & 0.37 \\
\hline Outside CZ — Total (Work) & 0.00 & 0.03 & 0.08 & 0.19 & 0.37 & 0.55 & 0.73 & 0.82 & 1.00 & 0.39 \\
\hline CZ Employment/Residents & 0.63 & 0.87 & 0.91 & 0.97 & 1.00 & 1.01 & 1.03 & 1.04 & 1.12 & 0.98 \\
\hline
\end{tabular}

Tabulations on 3,111 counties and 709 commuting zones. The first row shows the fraction of residents that work outside the county. The second row shows the fraction of workers who live outside the county. The third row shows the ratio of county employment to county residents. The forth row shows the fraction of residents that work outside the county who also work outside the county's CZ. The fifth row shows the fraction of workers that live outside the county who also live outside the county's CZ. The sixth row shows the ratio of CZ employment to CZ residents across all 709 CZ. p5, p10 etc refer to the 5th, 10th etc percentiles of the distribution.

Table 1: Commuting Across Counties and Commuting Zones

beyond $\mathrm{CZ}$ boundaries that again varies in importance across locations. For the median county, around 33 percent of the workers who commute outside their county of residence also commute outside their CZ of residence (fourth row, fifth column), while around 37 percent of the workers who commute outside their county of workplace also commute outside their $\mathrm{CZ}$ of workplace (fifth row, fifth column). For the $\mathrm{CZ}$ at the 90th percentile, these two figures rise to 79 and 73 percent respectively (seventh column). Although the ratio of employment to residents $(L / R)$ by construction varies less across CZs than across counties, we still find substantial variation from 0.63 to 1.12 , which we show below is sufficient to generate substantial heterogeneity in local employment elasticities.

To provide further evidence on commuting that is independent of our model, we decompose changes in employment in each county over the period 1990-2010 into the percentage contributions of migration and commuting (as shown in Subsection C.2 of the web appendix). For the median county, around 39 percent of the observed changes in employment are due to changes in commuting patterns, with this percentage varying substantially across counties from close to zero to close to one. For more than one third of counties, the contribution from commuting is larger than that from migration. Therefore these results confirm the quantitative importance of commuting in accounting for observed changes in employment over time.

Using land market clearing (5) and the price index (9), the gravity equation for the commuting probability (11) in the model can be written as

$$
\lambda_{n i}-\frac{\mathcal{B}_{n i}\left(\frac{L_{n}}{\pi_{n n}}\right)^{-\frac{\alpha \epsilon}{\sigma-1}} A_{n}^{\alpha \epsilon} w_{n}^{-\alpha \epsilon} \bar{v}_{n}^{-\epsilon(1-\alpha)}\left(\frac{R_{n}}{H_{n}}\right)^{-\epsilon(1-\alpha)} w_{i}^{\epsilon}}{\sum_{r \in N} \sum_{s \in N} \mathcal{B}_{r s}\left(\frac{L_{r}}{\pi_{r r}}\right)^{-\frac{\alpha \epsilon}{\sigma-1}} A_{r}^{\alpha \epsilon} w_{r}^{-\alpha \epsilon} \bar{v}_{r}^{-\epsilon(1-\alpha)}\left(\frac{R_{r}}{H_{r}}\right)^{-\epsilon(1-\alpha)} w_{s}^{\epsilon}}=0
$$

where $\mathcal{B}_{n i} \equiv B_{n i} \kappa_{n i}^{-\epsilon}$ is a composite parameter that captures the ease of commuting. The commuting probabilities (19) provide a system of $N \times N$ equations that can be solved for a unique matrix of $N \times N$ 
values of the ease of commuting $\left(\mathcal{B}_{n i}\right)$. The next proposition shows this formally.

Proposition 4 (Amenities Inversion) Given the share of consumption goods in expenditure ( $\alpha)$, the heterogeneity in location preferences $(\epsilon)$, the observed data on wages, employment, trade shares, average residential income, residents and land area $\left\{w_{i}, L_{i}, \pi_{i i}, \bar{v}_{i}, R_{i}, H_{i}\right\}$, there exist unique values of the ease of commuting $\left(\mathcal{B}_{n i} \equiv B_{n i} \kappa_{n i}^{-\epsilon}\right)$ for each pair of locations $n$ and $i$ that are consistent with the data being an equilibrium of the model.

The resulting solutions for the ease of commuting $\left(\mathcal{B}_{n i}\right)$ capture all factors that make a pair of residence and workplace locations more or less attractive conditional on the observed wages, employment, trade shares, average residential income, residents and land area (e.g. attractive scenery, distance and transport infrastructure). Together productivity $\left(A_{i}\right)$ and the ease of commuting $\left(\mathcal{B}_{n i}\right)$ correspond to structural residuals that ensure that the model exactly replicates the observed data given the parameters.

To estimate the heterogeneity in location preferences $(\epsilon)$, we model the determinants of the bilateral ease of commuting. For bilateral pairs with positive commuting flows, we partition the ease of commuting $\left(\mathcal{B}_{n i}\right)$ into four components: (i) a residence component $\left(\mathbb{B}_{n}\right)$, (ii) a workplace component $\left(\mathbb{B}_{i}\right)$, (iii) a component that is related to distance $\left(\right.$ dist $\left._{n i}^{-\phi}\right)$, and (iv) an orthogonal component $\left(\mathbb{B}_{n i}\right)$

$$
\log \mathcal{B}_{n i} \equiv \log \left(B_{n i} \kappa_{n i}^{-\epsilon}\right)=\log \mathbb{B}_{n}+\log \mathbb{B}_{i}-\phi \log \left(\text { dist }_{n i}\right)+\log \mathbb{B}_{n i}
$$

We can always undertake this statistical decomposition of the ease of commuting $\left(\log \mathcal{B}_{n i}\right)$, where the error term $\left(\log \mathbb{B}_{n i}\right)$ is orthogonal to distance by construction, because the reduced-form coefficient on $\log$ distance $(-\phi)$ captures any correlation of either $\log$ bilateral amenities $\left(\log B_{n i}\right)$ and/or $\log$ bilateral commuting costs $\left(\log \left(\kappa_{n i}^{-\epsilon}\right)\right)$ with log distance. For bilateral pairs with zero commuting, the model implies negligible amenities $\left(B_{n i} \rightarrow 0\right)$ and/or prohibitive commuting costs $\left(\kappa_{n i} \rightarrow \infty\right){ }^{22}$

In the first step of our gravity equation estimation, we use this decomposition (20) and our expression for commuting flows (11) to estimate the reduced-form distance coefficient $(-\phi)$ :

$$
\log \lambda_{n i}=g_{0}+\eta_{n}+\mu_{i}-\phi \log \text { dist }_{n i}+\log \mathbb{B}_{n i}
$$

where the residence fixed effect $\left(\eta_{n}\right)$ captures the consumption goods price index $\left(P_{n}\right)$, the price of residential land $\left(Q_{n}\right)$, and the residence component of the ease of commuting $\left(\mathbb{B}_{n}\right)$; the workplace fixed effect $\left(\mu_{i}\right)$ captures the wage $\left(w_{i}\right)$ and the workplace component of the ease of commuting $\left(\mathbb{B}_{i}\right)$; the constant $g_{0}$ captures the denominator of $\lambda_{n i}$ and is separately identified because we normalize the residence and workplace fixed effects to sum to zero; and the error term $\left(\log \mathbb{B}_{n i}\right)$ is orthogonal to $\log$ distance, because all effects of log distance on the composite ease of commuting are captured in the reduced-form distance coefficient $(-\phi){ }^{23}$

\footnotetext{
${ }^{22}$ As for goods trade above, one interpretation is that commuting requires prior investments in transport infrastructure that are not modeled here. We adopt our specification for tractability, but other explanations for zero commuting flows include a
} 


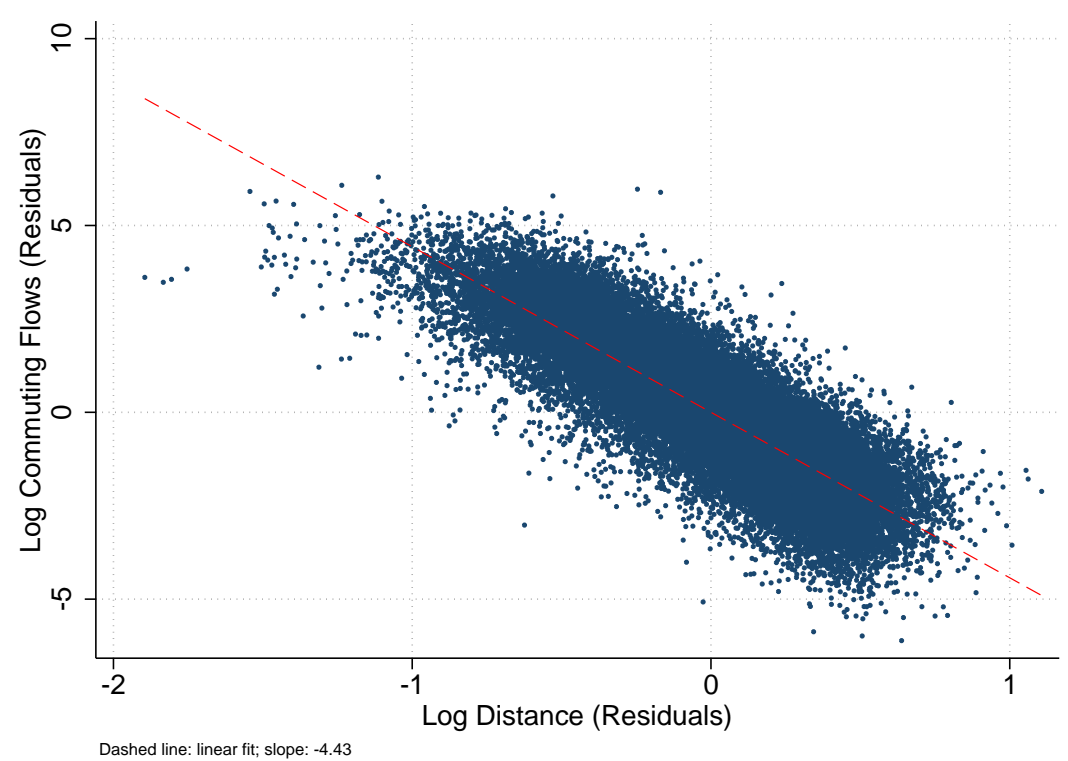

Figure 3: Gravity in Commuting Between Counties

Estimating the gravity equation (21) for all bilateral pairs with positive commuters using OLS, we find a regression R-squared of 0.80. In Figure 3, we display the conditional relationship between log commuters and $\log$ distance, after removing residence and workplace fixed effects from both log commuters and log distance. Consistent with the existing empirical literature on commuting, we find that the $\log$ linear functional form provides a good approximation to the data, with a tight and approximately linear relationship between the two variables, and an estimated coefficient on log distance of $-\phi=-4.43$. This estimated coefficient is substantially larger than the corresponding coefficient for trade in goods of $-(\sigma-1) \psi=-1.29$, which is consistent with the view that transporting people is considerably more costly than transporting goods, in line with the substantial opportunity cost of time spent commuting.

To identify the Fréchet shape parameter $(\epsilon)$, the second step of our gravity equation estimation uses additional structure from the model, which implies that the workplace fixed effects $\mu_{i}$ depend on wages $\left(w_{i}\right)$ and the workplace component of the ease of commuting $\left(\mathbb{B}_{i}\right)$ :

$$
\log \lambda_{n i}=g_{0}+\eta_{n}+\epsilon \log w_{i}-\phi \log d i s t_{n i}+\log u_{n i}
$$

where the error term is given by $\log u_{n i} \equiv \log \mathbb{B}_{i}+\log \mathbb{B}_{n i}$.

We estimate the gravity equation (22) imposing $\phi=4.43$ from our estimates above and identify $\epsilon$ from the coefficient on wages. Estimating (22) using OLS is potentially problematic, because workplace wages $\left(w_{i}\right)$ depend on the supply of commuters, which in turn depends on amenities that appear in the error term $\left(\log u_{n i}\right)$. Therefore we instrument $\log w_{i}$ with the $\log$ productivities $\log A_{i}$ that we recovered from the condition (17) equating income and expenditure above, using the fact that the model implies that

support for the distribution of idiosyncratic preferences that is bounded from above or granularity.

${ }^{23}$ In Subsection B.10 of the web appendix, we generalize this specification to introduce congestion that is a power function of the volume of commuters. We show that this generalization affects the interpretation of the estimated coefficients in the gravity equation, but leaves the model's prediction of heterogeneous local employment elasticities unchanged. 
productivity satisfies the exclusion restriction of only affecting commuting flows through wages. Our TwoStage-Least-Squares estimate of the Fréchet shape parameter for the heterogeneity of worker preferences is $\epsilon=3.30 .{ }^{24}$ The tight fit shown in Figure 3 makes us confident that our parametrization of the composite ease of commuting in terms of distance fits the data quite well.

For the one remaining parameter of the model, the share of housing in consumer expenditure, we assume a central value from Bureau of Economic Analysis of $1-\alpha=0.40$ percent. $^{25}$ Using our assumption of Cobb-Douglas utility and our interpretation of land as geographical land area, in Subsection C.3 of the web appendix, we show that the model's predictions for land prices are strongly positively correlated with observed county median housing values. In the next section, we also relax these assumptions to introduce a positive supply elasticity for developed land.

\section{Local Employment Elasticities}

Having quantified the model, we now explore its implications for local employment elasticities. In Subsection 4.1, we undertake counterfactuals to evaluate the elasticity of local employment in each county with respect to a local labor demand shock (a productivity shock in the model). We find that the model predicts substantial heterogeneity in this elasticity across counties. In Subsection 4.2, we show that this heterogeneity is not well explained by standard empirical controls, but is well explained by measures of connections to other counties in commuting networks. In Subsection 4.3, we show that these results are robust to introducing heterogeneity in the supply of developed land across locations. In Subsection 4.4, we demonstrate that these heterogeneous local employment elasticities correspond to heterogeneous treatment effects in reduced-form regressions for the impact of local labor demand shocks. In Subsection 4.5, we provide independent evidence in support of these predictions of the model using the natural experiment of million dollar plants (MDPs), as examined in GHM (2010). We find heterogeneous treatment effects that take exactly the form implied by the model, such that the opening of MDPs has larger effects on employment in counties more open to commuting.

\footnotetext{
${ }^{24}$ We find that the Two-Stage-Least-Squares estimates are larger than the OLS estimates, consistent with the idea that bilateral commutes with attractive amenities have a higher supply of commuters and hence lower wages. The first-stage F-Statistic for productivity is 228.1, confirming that productivity is a powerful instrument for wages. Note that one could have estimated jointly $\phi$ and $\epsilon$ from the restricted equation (22) directly. Our approach, however, imposes only the minimal set of necessary restrictions at every step: we estimate a flexible gravity structure to identify $\phi$ in (21), and a slightly less general specification (where workplace fixed effects are restricted to capture only variation in workplace wages) to identify $\epsilon$. Estimating the restricted equation (22) directly would yield very similar results: we find $\epsilon=3.19$ and $\phi=4.09$.

${ }^{25}$ Using these assumed parameter values, we correlate our measures of residential amenities with observable proxies for this variable. We regress the solutions for the bilateral ease of commuting $\left(\mathcal{B}_{n i}\right)$ from equation (19) on residence and workplace fixed effects and bilateral distance. We use the residence fixed effect as our measure of residential amenities. Regressing this measure on violent crimes per resident, we find a negative and statistically significant coefficient (standard error) of -0.48 (0.10). Crime data is from the U.S. Department of Justice (2007).
} 


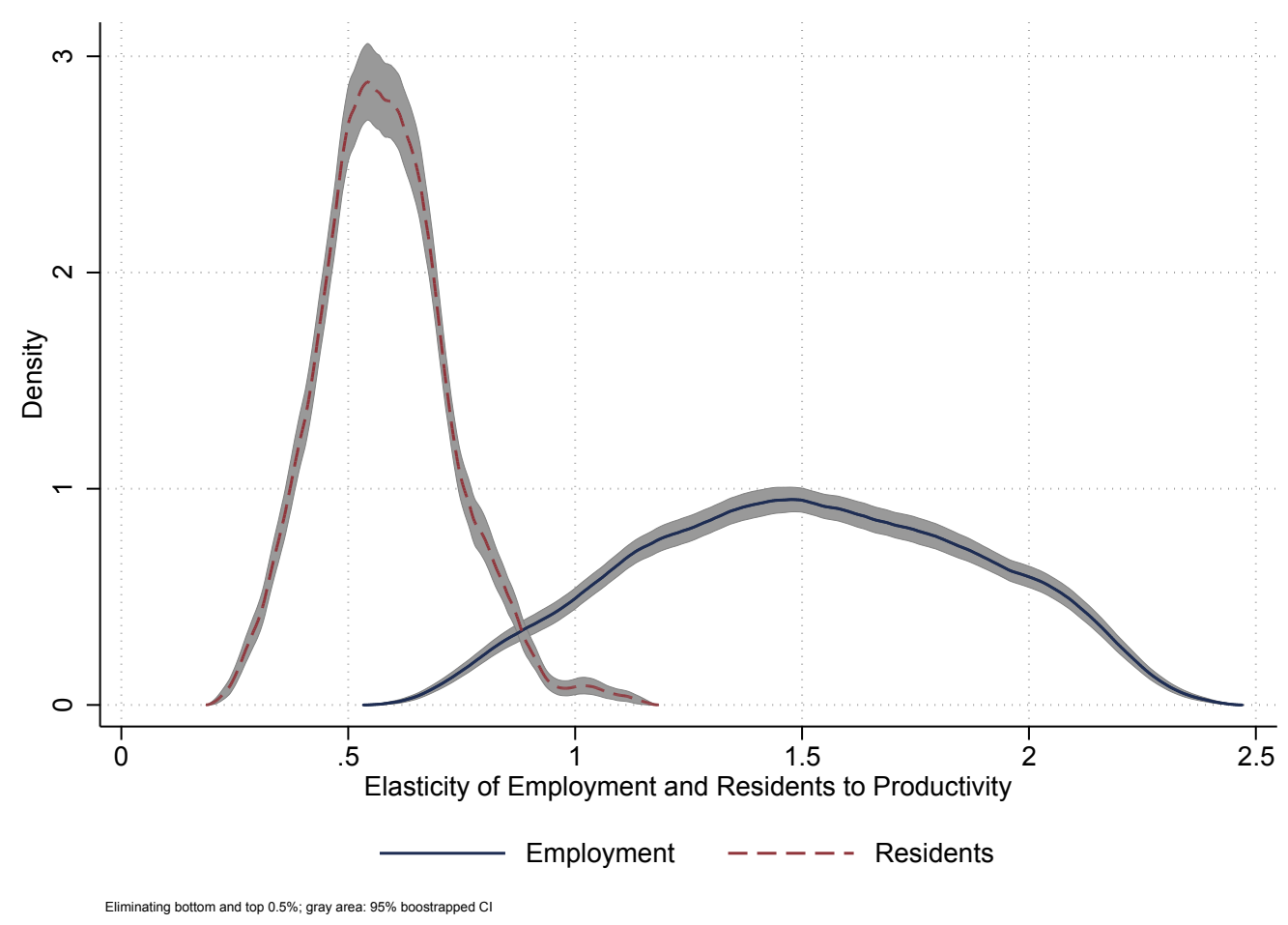

Figure 4: Kernel density for the distribution of employment and residents elasticities in response to a productivity shock across counties

\subsection{Heterogeneity in Local Employment Elasticities}

To provide evidence on local employment elasticities, we compute 3,111 counterfactual exercises where we shock each county with a 5 percent productivity shock (holding productivity in all other counties and holding all other exogenous variables constant). ${ }^{26}$ Figure 4 shows the estimated kernel density for the distribution of the general equilibrium elasticity of employment with respect to the productivity shock across these treated counties (solid blue line). We also show the 95 percent confidence intervals around this estimated kernel density (gray shading). The mean estimated local employment elasticity of around 1.52 is greater than one because of home market effects and commuting. Around this mean, we find substantial heterogeneity in the predicted effects of the productivity shock, which vary from close to 0.5 to almost 2.5. This variation is surprisingly large. It implies that taking a local employment elasticity estimated for one group of counties and applying that elasticity to another group of counties can lead to substantial discrepancies between the true and predicted impacts of a productivity shock.

To provide a point of comparison, Figure 4 also includes the general equilibrium elasticity of residents in a county with respect to the same 5 percent productivity shock in that county (again holding other parameters constant). Again we show the estimated kernel density across the 3,111 treated counties (dashed red line) and the 95 percent confidence intervals (gray shading). We find substantial differences between the employment and residents elasticities, with the residents elasticity having less dispersion and ranging from around 0.2 to 1.2. Since employment and residents can only differ through commuting, this by itself

\footnotetext{
${ }^{26}$ We have experimented with shocks of $1 \%$ and $10 \%$ as well, with essentially unchanged results.
} 
suggests that the heterogeneity in the local employment elasticity is largely driven by commuting links between counties. In Section C.8 of the web appendix, we provide further evidence that this is indeed the case by simulating productivity shocks in a counterfactual world without commuting between counties. Even in such a counterfactual world, we expect local employment elasticities to be heterogeneous, because counties differ substantially in terms of their initial shares of US employment. However, we find substantially less heterogeneity in local employment elasticities in this counterfactual world than in the actual world with commuting. In fact, the resulting distribution of employment (and residential) elasticities is similar to the one for residential elasticities in Figure 4.

In Subsection C.6 of the web appendix, we show that this heterogeneity in local employment elasticities remains if we shock counties with patterns of spatially correlated shocks reproducing the industrial composition of the U.S. economy. In Subsection C.10 of the web appendix, we find a similar pattern of results if we replicate our entire quantitative analysis for $\mathrm{CZs}$ rather than counties. Both sets of results are consistent with the fact that heterogeneous local employment elasticities are a generic prediction of a gravity equation for commuting (as shown in Subsection B.8 of the web appendix). Although CZ boundaries are drawn to minimize commuting, they inevitably cannot perfectly capture the rich geography of commuting flows implied by the gravity equation.

\subsection{Explaining the Heterogeneity in Local Employment Elasticities}

We now use the model to provide intuition on the determinants of the general equilibrium local employment elasticities, $\frac{d L_{i}}{d A_{i}} \frac{A_{i}}{L_{i}}$. We also use the structure of the model to determine a set of variables that can be used empirically to account for the estimated heterogeneity in the distribution of local employment elasticities. To do so, we compute partial equilibrium elasticities of own wages and own employment with respect to the productivity shock. These partial equilibrium elasticities capture the direct effect of a productivity shock on wages, employment and residents in the treated location, holding constant all other endogenous variables at their values in the initial equilibrium. ${ }^{27}$ Hence, although potentially useful to provide intuition, or as empirical controls, they do not account for all the rich set of interactions in the model captured by the general equilibrium elasticities presented in Figure 4.

If we hold constant all variables except for $w_{i}, L_{i}$, and $R_{i}$ in the treated county $i$, the partial elasticity of employment with respect to the productivity shock is the product of the partial elasticity of employment with respect to wages and the partial elasticity of wages with respect to the productivity shock ${ }^{28}$

$$
\frac{\partial L_{i}}{\partial A_{i}} \frac{A_{i}}{L_{i}}=\frac{\partial L_{i}}{\partial w_{i}} \frac{w_{i}}{L_{i}} \cdot \frac{\partial w_{i}}{\partial A_{i}} \frac{A_{i}}{w_{i}}
$$

From the equality between income and expenditure (8), the partial elasticity of wages with respect to the

\footnotetext{
${ }^{27}$ See Section B.7 in the web appendix for the derivation of these partial equilibrium elasticities.

${ }^{28}$ Note that we use the partial derivative symbol, $\frac{\partial L_{i}}{\partial A_{i}} \frac{A_{i}}{L_{i}}$, to denote the partial equilibrium elasticity when we allow $w_{i}, L_{i}$, and $R_{i}$ to change but keep other variables in all other counties fixed.
} 
productivity shock is given by

$$
\frac{\partial w_{i}}{\partial A_{i}} \frac{A_{i}}{w_{i}}=\frac{(\sigma-1) \sum_{n \in N}\left(1-\pi_{n i}\right) \xi_{n i}}{\left[1+(\sigma-1) \sum_{n \in N}\left(1-\pi_{n i}\right) \xi_{n i}\right]+\left[1-\sum_{n \in N}\left(1-\pi_{n i}\right) \xi_{n i}\right] \frac{\partial L_{i}}{\partial w_{i}} \frac{w_{i}}{L_{i}}-\xi_{i i} \frac{\partial R_{i}}{\partial w_{i}} \frac{w_{i}}{R_{i}}} .
$$

where $\xi_{n i}=\pi_{n i} \alpha \bar{v}_{n} R_{n} / w_{i} L_{i}$ is the share of location $i$ 's revenue from market $n$.

The intuition for the response of wages to the productivity shock can be seen most clearly for the case when $\frac{\partial L_{i}}{\partial w_{i}} \frac{w_{i}}{L_{i}} \approx 0$ and $\frac{\partial R_{i}}{\partial w_{i}} \frac{w_{i}}{R_{i}} \approx 0$. From the terms in $(\sigma-1) \sum_{n \in N}\left(1-\pi_{n i}\right) \xi_{n i}$, the elasticity of wages with respect to productivity is high when location $i$ accounts for a small share of expenditure ( $\operatorname{small} \pi_{n i}$ ) in markets $n$ that account for a large share of its revenue (high $\xi_{n i}$ ). In these circumstances, the productivity shock reduces the prices of location $i$ 's goods and results in only a small reduction in the goods price indices (small $\pi_{n i}$ ) in its main markets (high $\xi_{n i}$ ). ${ }^{29}$ Therefore the productivity shock leads to a large increase in the demand for location $i$ 's goods and hence in its wages. Thus $\sum_{n \in N}\left(1-\pi_{n i}\right) \xi_{n i}$ provides a measure of location $i$ 's linkages to other locations in goods markets.

From the commuter market clearing condition (14), the partial elasticity of employment with respect to wages is

$$
\frac{\partial L_{i}}{\partial w_{i}} \frac{w_{i}}{L_{i}}=\epsilon \sum_{n \in N}\left(1-\lambda_{n i \mid n}\right) \vartheta_{n i}+\vartheta_{i i}\left(\frac{\partial R_{i}}{\partial w_{i}} \frac{w_{i}}{R_{i}}\right)
$$

where $\vartheta_{n i}=\lambda_{n i \mid n} R_{n} / L_{i}$ is the share of commuters from residence $n$ in workplace $i$ 's employment.

The intuition for the response of employment to wages can be seen most clearly for the case when $\frac{\partial R_{i}}{\partial w_{i}} \frac{w_{i}}{R_{i}} \approx 0$. From the term in $\epsilon \sum_{n \in N}\left(1-\lambda_{n i \mid n}\right) \vartheta_{n i}$, the elasticity of employment with respect to wages is high when workplace $i$ employs a small share of commuters (small $\lambda_{n i \mid n}$ ) from residences $n$ that supply a large fraction of its employment (high $\vartheta_{n i}$ ). In these circumstances, location $i$ 's wage increase makes it a more attractive workplace and results in only a small increase in commuter market access $\left(\operatorname{small} \lambda_{n i \mid n}\right)$ in its main sources of commuters (high $\vartheta_{n i}$ ). ${ }^{30}$ Therefore the increase in wages leads to a large increase in commuters to workplace $i$ and hence in its employment. Thus $\sum_{n \in N}\left(1-\lambda_{n i \mid n}\right) \vartheta_{n i}$ provides a measure of workplace $i$ 's linkages to other locations through commuting. In Subsection B.8 of the web appendix, we show that this partial elasticity takes the same form in the class of theoretical models consistent with a gravity equation for commuting flows.

Using (12), the partial elasticity of residents with respect to wages is

$$
\frac{\partial R_{i}}{\partial w_{i}} \frac{w_{i}}{R_{i}}=\epsilon\left(\frac{\lambda_{i i}}{\lambda_{R i}}-\lambda_{L i}\right)
$$

which also has an intuitive interpretation. A higher wage in location $i$ makes it a more attractive workplace and increases its employment. Whether this increase in location $i$ 's employment leads to an increase in its

\footnotetext{
${ }^{29}$ These price indices summarize the price of competing varieties in each market. Note that the elasticity of the price index (9) in location $n$ with respect to wages in location $i$ is $\left(\partial P_{n} / \partial w_{i}\right)\left(w_{i} / P_{n}\right)=\pi_{n i}$.

${ }^{30}$ Commuter market access appears in the numerator of the residential choice probabilities $\left(\lambda_{R n}\right.$ in (12)) and summarizes access to employment opportunities: $W_{n}=\left[\sum_{s \in N} B_{n s}\left(w_{s} / \kappa_{n s}\right)^{\epsilon}\right]^{1 / \epsilon}$. Note that the elasticity of commuter market access in location $n$ with respect to wages in location $i$ is $\left(\partial W_{n} / \partial w_{i}\right)\left(w_{i} / W_{n}\right)=\lambda_{n i \mid n}$.
} 
share of residents depends on the fraction of residents who work locally $\left(\lambda_{i i} / \lambda_{R i}\right)$ relative to location $i$ 's overall share of employment $\left(\lambda_{L i}\right)$. Thus $\left(\lambda_{i i} / \lambda_{R i}-\lambda_{L i}\right)$ provides a measure of location $i$ 's linkages to other locations through migration.

Combining the three elasticities in equations (24), (25), and (26), we obtain closed-form solutions for the partial equilibrium elasticities of wages, employment and residents to a productivity shock. These partial equilibrium elasticities depend solely on the observed values of variables in the initial equilibrium: residential employment shares $\left(\lambda_{R i}\right)$, conditional commuting probabilities $\left(\lambda_{n i \mid n}\right)$, employment shares $\left(\vartheta_{n i}\right)$, trade shares $\left(\pi_{n i}\right)$ and revenue shares $\left(\xi_{n i}\right)$.

When we undertake our counterfactuals, we solve for the full general equilibrium effect of the productivity shock to each county. But these partial equilibrium elasticities in terms of observed variables have substantial explanatory power in predicting the impact of the productivity shock across locations, as now shown in Table 2. In Column (1) we regress our general equilibrium elasticities on a constant, which captures the mean employment elasticity across the 3,111 treated counties. In Columns (2) through (4) we attempt to explain the heterogeneity in local employment elasticities using standard county controls. In Column (2) we include log county employment as a control for the size of economic activity in a county. In Column (3) we also include log county wages and log county land area. In Column (4) we also include the average wage and total employment in neighboring counties. Although these controls are all typically statistically significant, we find that they are not particularly successful in explaining the variation in employment elasticities. Adding a constant and all these controls yields an R-squared of only about 0.5 in Column (4). Clearly, there is substantial variation not captured by these controls.

In the remaining columns of the table we attempt to explain the heterogeneity in local employment elasticities using the partial equilibrium elasticities derived above. In Column (5) we first use the intuition (obtained by comparing the distributions in Figure 4) that commuting is important. As a summary statistic of the lack of commuting links of a county we use $\lambda_{i i \mid}$, namely, the share of workers that work in $i$ conditional on living in $i$. The weaker the commuting links of a county, the higher $\lambda_{i i \mid i}$, which reduces the local employment elasticity of that county. This is exactly what we find in Column (5). Furthermore, this variable alone yields an R-squared of 0.89 , nearly double the R-squared in the regression where we include all the standard controls. ${ }^{31}$ Therefore, although the model incorporates several forms of spatial linkages (including trade and migration), we find that the heterogeneity in local employment elasticities is mainly explained by commuting linkages, which is consistent with our gravity equation estimates, where commuting is substantially more local (higher distance coefficient) than goods trade. ${ }^{32}$

The partial equilibrium local elasticities computed above allow us to do better than just adding a summary measure of commuting links as the explanatory variable. In Column (6) we relate the vari-

\footnotetext{
${ }^{31}$ To provide further evidence on the magnitude of these effects, Table C.3 in Section C.4 of the web appendix reports the same regressions as in Table 2 but using standardized coefficients. We find that a one standard deviation change in the own commuting share $\left(\lambda_{i i \mid i}\right)$ leads to around a one standard deviation change in the local employment elasticity.

${ }^{32}$ In Subsection B.8 of the web appendix, we report kernel density estimates for the distribution of the partial equilibrium measure of commuting linkages $\sum_{n \in N}\left(1-\lambda_{n i \mid n}\right) \vartheta_{n i}$ that is a generic prediction of any commuting gravity equation. We show a similar distribution of heterogeneous local employment elasticities to that in Figure 4 above, again confirming that this heterogeneity is driven by commuting linkages.
} 
ation in local employment elasticities to the measure of commuting linkages suggested by the model, $\sum_{n \in N}\left(1-\lambda_{n i \mid n}\right) \vartheta_{n i}$. We also add the measures of migration and trade linkages suggested by the model, $\left(\lambda_{i i} / \lambda_{R i}-\lambda_{L i}\right)$ and $\frac{\partial w_{i}}{\partial A_{i}} \frac{A_{i}}{w_{i}}$. Including these partial equilibrium measures of linkages further increases the $\mathrm{R}$-squared to around 93 percent of the variation in the general equilibrium elasticity. Counties that account for a small share of commuters (small $\lambda_{n i \mid n}$ ) from their main suppliers of commuters (high $\vartheta_{n i}$ ) have higher employment elasticities. In Column (7), we use the product of $\frac{\partial w_{i}}{\partial A_{i}} \frac{A_{i}}{w_{i}}$ and the first two terms rather than each term separately. This restriction yields similar results and confirms the importance of commuting linkages and, to a lesser extent, the interaction between migration and goods linkages. Finally, in the last two columns we combine these partial equilibrium elasticities with the standard controls we used in the first four columns. Clearly, although all variables are significant, these standard controls add little once we control for the partial equilibrium elasticities.

In sum, Table 2 shows that the heterogeneity in partial equilibrium elasticities is not well explained by standard county controls. In contrast, adding a summary statistic of commuting, or the partial equilibrium elasticities we propose above, can go a long way in explaining this heterogeneity.

\subsection{Positive Developed Land Supply Elasticities}

In the baseline version of the model, we interpret the non-traded amenity as simply land, which is in perfectly inelastic supply. In this section, we develop an extension of the model, in which we interpret the non-traded amenity as "developed" land and allow for a positive developed land supply elasticity that can differ across locations.

We continue to assume the same specification of preferences, production and commuting decisions as in Section 2 above. We introduce a positive developed land supply elasticity by following Saiz (2010) in assuming that the supply of land $\left(H_{n}\right)$ for each residence $n$ depends on the endogenous price of land $\left(Q_{n}\right)$ as well as on the exogenous characteristics of locations $\left(\bar{H}_{n}\right)$ :

$$
H_{n}=\bar{H}_{n} Q_{n}^{\eta_{n}}
$$

where $\eta_{n} \geq 0$ is the developed land supply elasticity, which we allow to vary across locations; $\eta_{n}=0$ is our baseline specification of a perfectly inelastic land supply; and $\eta_{n} \rightarrow \infty$ is the special case of a perfectly elastic land supply.

Introducing a positive and heterogeneous developed land supply elasticity only affects one of the conditions for general equilibrium in the model, namely the land market clearing condition. Using the supply function for land (27) in the land market clearing condition (5), we obtain the following generalization of our earlier expression for the equilibrium price of land $\left(Q_{n}\right)$ :

$$
Q_{n}=\left((1-\alpha) \frac{\bar{v}_{n} R_{n}}{\bar{H}_{n}}\right)^{\frac{1}{1+\eta_{n}}}
$$

where our baseline specification corresponds to the special case in which $\eta=0$. Therefore, when under- 


\begin{tabular}{|c|c|c|c|c|c|c|c|c|c|}
\hline & 1 & 2 & 3 & 4 & 5 & 6 & 7 & 8 & 9 \\
\hline Dependent Variable: & \multicolumn{9}{|c|}{ Elasticity of Employment } \\
\hline $\log L_{i}$ & & $\begin{array}{l}-0.003 \\
(0.005)\end{array}$ & $\begin{array}{l}0.009 * \\
(0.004)\end{array}$ & $\begin{array}{c}-0.054 * * \\
(0.005)\end{array}$ & & & & $\begin{array}{l}0.037^{* *} \\
(0.002)\end{array}$ & $\begin{array}{l}0.033^{* *} \\
(0.002)\end{array}$ \\
\hline $\log w_{i}$ & & & $\begin{array}{c}-0.201 * * \\
(0.028)\end{array}$ & $\begin{array}{c}-0.158 * * \\
(0.027)\end{array}$ & & & & $\begin{array}{c}-0.257 * * \\
(0.009)\end{array}$ & $\begin{array}{c}-0.263^{* *} \\
(0.009)\end{array}$ \\
\hline $\log H_{i}$ & & & $\begin{array}{r}-0.288 * * \\
(0.006)\end{array}$ & $\begin{array}{c}-0.172 * * \\
(0.009)\end{array}$ & & & & $\begin{array}{c}0.003 \\
(0.003)\end{array}$ & $\begin{array}{c}0.009 * * \\
(0.003)\end{array}$ \\
\hline $\log L_{,-i}$ & & & & $\begin{array}{c}0.118^{* *} \\
(0.007)\end{array}$ & & & & $\begin{array}{c}-0.027 * * \\
(0.003)\end{array}$ & $\begin{array}{r}-0.027 * * \\
(0.003)\end{array}$ \\
\hline $\log \bar{w}_{-i}$ & & & & $\begin{array}{c}0.204^{* *} \\
(0.047)\end{array}$ & & & & $\begin{array}{c}0.163^{* *} \\
(0.015)\end{array}$ & $\begin{array}{r}0.207 * * \\
(0.015)\end{array}$ \\
\hline$\lambda_{i i \mid i}$ & & & & & $\begin{array}{c}-2.047 * * \\
(0.013)\end{array}$ & & & & \\
\hline$\sum_{n \in N}\left(1-\lambda_{n i \mid n}\right) \vartheta_{n i}$ & & & & & & $\begin{array}{l}2.784 * * \\
(0.092)\end{array}$ & & $\begin{array}{r}2.559 * * \\
(0.098)\end{array}$ & \\
\hline$\vartheta_{i i}\left(\frac{\lambda_{i i}}{\lambda_{R i}}-\lambda_{L i}\right)$ & & & & & & $\begin{array}{c}0.915^{* *} * \\
(0.090)\end{array}$ & & $\begin{array}{c}0.605 * * \\
(0.096)\end{array}$ & \\
\hline$\frac{\partial w_{i}}{\partial A_{i}} \frac{A_{i}}{w_{i}}$ & & & & & & $\begin{array}{r}-1.009^{* *} \\
(0.046)\end{array}$ & & $\begin{array}{c}-0.825^{* *} \\
(0.053)\end{array}$ & \\
\hline$\frac{\partial w_{i}}{\partial A_{i}} \frac{A_{i}}{w_{i}} \cdot \sum_{r \in N}\left(1-\lambda_{r n \mid r}\right) \vartheta_{r n}$ & & & & & & & $\begin{array}{c}1.038 * * \\
(0.036)\end{array}$ & & $\begin{array}{c}1.100 * * \\
(0.048)\end{array}$ \\
\hline$\frac{\partial w_{i}}{\partial A_{i}} \frac{A_{i}}{w_{i}} \cdot \vartheta_{i i}\left(\frac{\lambda_{i i}}{\lambda_{R i}}-\lambda_{L i}\right)$ & & & & & & & $\begin{array}{c}-0.818 * * \\
(0.036)\end{array}$ & & $\begin{array}{c}-0.849 * * \\
(0.047)\end{array}$ \\
\hline constant & $\begin{array}{l}1.515^{* *} \\
(0.007)\end{array}$ & $\begin{array}{l}1.545^{* *} \\
(0.044)\end{array}$ & $\begin{array}{c}5.683 * * \\
(0.275)\end{array}$ & $\begin{array}{l}1.245^{* *} \\
(0.437)\end{array}$ & $\begin{array}{l}2.976^{* *} \\
(0.009)\end{array}$ & $\begin{array}{c}0.840 * * \\
(0.084)\end{array}$ & $\begin{array}{l}1.553 * * \\
(0.035)\end{array}$ & $\begin{array}{l}1.861 * * \\
(0.171)\end{array}$ & $\begin{array}{r}2.064 * * \\
(0.152)\end{array}$ \\
\hline $\begin{array}{l}R^{2} \\
N\end{array}$ & $\begin{array}{c}0.00 \\
3,111\end{array}$ & $\begin{array}{r}0.00 \\
3,111\end{array}$ & $\begin{array}{c}0.40 \\
3,111\end{array}$ & $\begin{array}{c}0.51 \\
3,081\end{array}$ & $\begin{array}{c}0.89 \\
3,111\end{array}$ & $\begin{array}{c}0.93 \\
3,111\end{array}$ & $\begin{array}{c}0.93 \\
3,111\end{array}$ & $\begin{array}{c}0.95 \\
3,081\end{array}$ & $\begin{array}{c}0.95 \\
3,081\end{array}$ \\
\hline
\end{tabular}

In this table, $L_{,-i} \equiv \sum_{n: d_{n i} \leq 120, n \neq i} L_{n}$ is the total employment in $i$ neighbors whose centroid is no more than $120 \mathrm{~km}$ away; $\bar{w}_{-i} \equiv \sum_{n: d_{n i} \leq 120, n \neq i} \frac{L_{n}}{L_{,-i}} w_{n}$ is the weigthed average of their workplace wage. $* p<0.05 ; * * p<0.01$.

Table 2: Explaining the general equilibrium local employment elasticities to a 5 percent productivity shock

taking counterfactuals in this extension of the model, we replace the land market clearing condition (5) from Section 2 above with the modified land market clearing condition (28) in the system of equations for the counterfactual equilibrium.

We use the empirical estimates of developed land supply elasticities from Saiz (2010), which are based on physical and regulatory constraints to the geographical expansion of developed land area. Physical constraints are measured using Geographical Information Systems (GIS) data on the location of bodies of water (oceans and lakes) and wetlands and the elevation of terrain (the fraction of surrounding land that has a slope above 15 percent). Regulatory constraints are measured using the Wharton Residential Urban Land Regulation Index, which captures the stringency of residential growth controls. Using these data, Saiz (2010) estimates developed land supply elasticities for 95 Metropolitan Statistical Areas (MSAs) in the United States. The population-weighted average of these land supply elasticities is 1.75 , and they 
range from 0.76 for the 10th ranked MSA (San Jose, CA) to 3.09 for the 85th ranked MSA (CharlotteGastonia-Rock Hill, NC-SC).

To incorporate these estimates into our quantitative analysis, we need to map these MSA-level estimates to our county-level data. Therefore we need to decide how to treat counties within multi-county MSAs and what to assume about counties that are not part of MSAs. We start by using the estimated Saiz elasticities where we have them (assuming the same elasticity for all counties within an MSA) and retaining our baseline specification of a zero elasticity for all other counties. One limitation of this specification is that the Saiz estimates are based on the expansion of the geographical boundaries of developed land for the MSA as a whole. However, in MSAs that consist of multiple counties, central counties that are surrounded by other already-developed counties cannot expand this geographical frontier. Another limitation is that counties outside MSAs typically can expand this geographical frontier. To address these limitations, in Subsection C.7 of the web appendix we consider a second specification in which we assume a land supply elasticity of zero for central counties within multi-county MSAs, the Saiz estimate for other counties in these MSA's and for single-county MSAs, and the median Saiz estimate across MSAs of 1.67 for all other counties. In further robustness checks, we considered variations in these assumptions, and found the same pattern of heterogeneous local employment elasticities in each of these variations. ${ }^{33}$

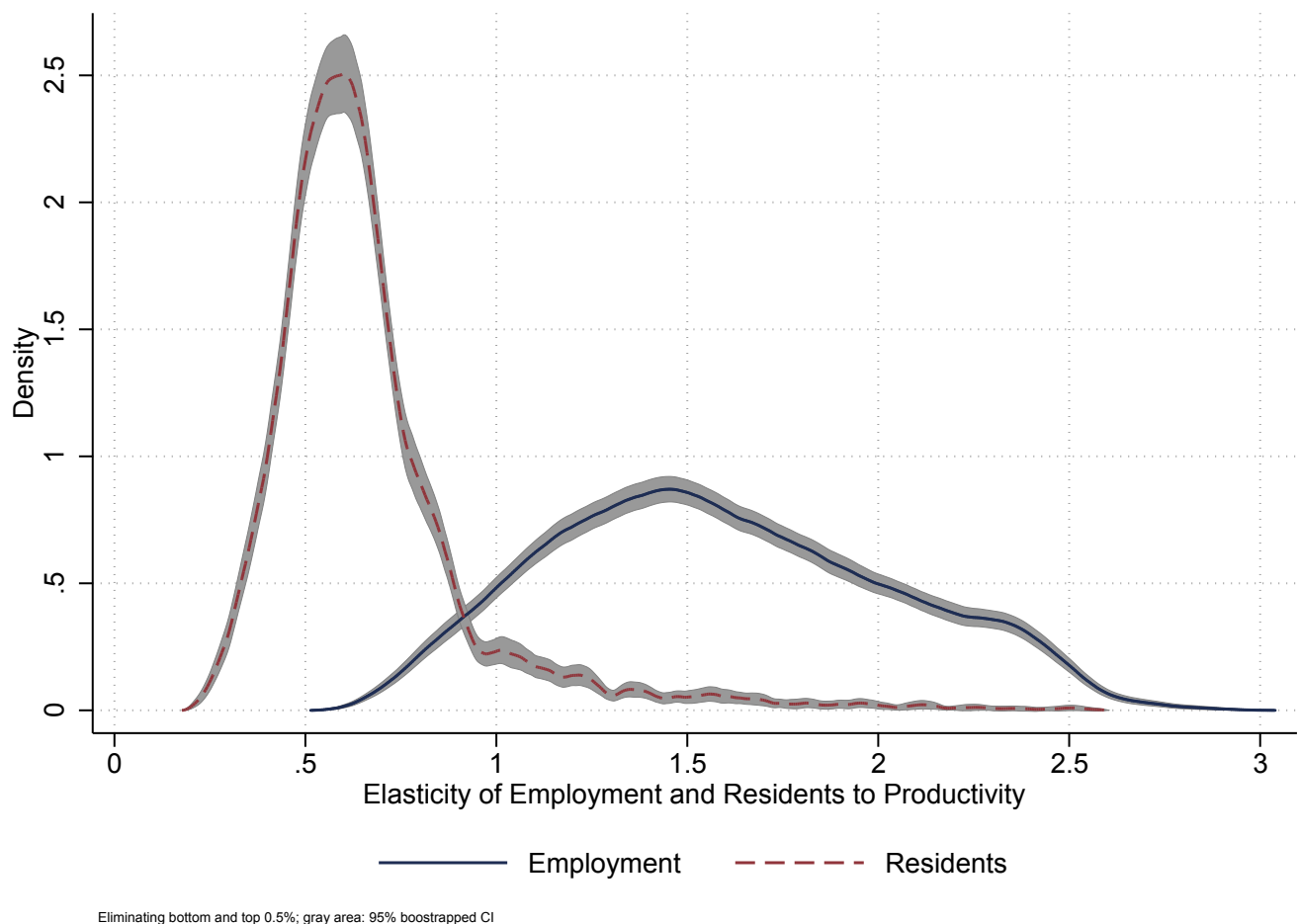

Note: For counties in the 95 MSAs for which Saiz (2010) estimates a housing supply elasticity, we use the elasticity estimated by Saiz. For counties outside the 95 MSAs, we use an elasticity of zero as in our benchmark case.

Figure 5: Kernel density for the distribution of employment and residents elasticities in response to a productivity shock across counties (Positive housing supply elasticity)

\footnotetext{
${ }^{33}$ For example, we modified the second specification by assuming that central counties in multi-county MSAs have the minimum housing supply elasticity across MSAs (0.6), and again found the same pattern of results.
} 
For each of these two specifications, we replicate our 3,111 counterfactual exercises where we shock each county with a 5 percent productivity shock (holding productivity in all other counties and holding all other exogenous variables constant). Figure 5 displays the results, and is analogous to Figure 4 in the paper. The figure shows the estimated kernel density for the distribution of the general equilibrium elasticity of both employment (blue solid line) and residents (red dashed line) with respect to the productivity shock across the treated counties. We also show the 95 percent confidence intervals around these estimated kernel densities (gray shading). Consistent with the results for our baseline specification, we continue to find substantial heterogeneity in local employment elasticities, confirming the robustness of our findings to allowing for a variable developed land supply elasticity. Relative to our baseline specification, both the employment and resident elasticities are somewhat larger in magnitude, as the elastic land supply dampens the congestion effect from increased residents, and allows both employment and residents to increase more than with a perfectly inelastic land supply. Compared with our baseline specification, we find more heterogeneity in the resident elasticity. This pattern of results is also intuitive. Our baseline specification focuses on one source of heterogeneity (commuting), which mainly affects local employment elasticities. In this robustness test, we introduce a second source of heterogeneity (through variable developed land supply elasticities), which mainly affects local resident elasticities (via residential land use). Therefore the main consequence of adding this second source of heterogeneity is to generate greater dispersion in residential elasticities. Nevertheless, the dispersion in employment elasticities remains of around the same magnitude as in our baseline specification. Furthermore, we continue to find substantial differences between the elasticities for residents and employment, where the only way that these two elasticities can differ from one another is through commuting.

\subsection{Measuring the Incidence of Local Labor Demand Shocks}

A large empirical literature is concerned with estimating the elasticity of local employment with respect to local labor demand shocks. The central specification in this empirical literature is a "differences-indifferences" specification across locations $i$ and time $t$ given by

$$
\Delta \ln Y_{i t}=a_{0}+a_{1} \mathbb{I}_{i t}+a_{2} X_{i t}+u_{i t}
$$

where $Y_{i t}$ is the outcome of interest (e.g. employment by workplace); $\mathbb{I}_{i t}$ is a measure of the local demand shock (treatment); $X_{i t}$ are controls; and $u_{i t}$ is a stochastic error. The coefficient on the treatment $a_{1}$ corresponds to the log change in the outcome of interest with respect to the local labor demand shock. This specification has a differences-in-differences interpretation, because the first difference is over time (before and after the shock), and the second difference is between treated and control counties.

We now compare the general equilibrium elasticities of employment with respect to the productivity shock in the model to the results of this type of reduced-form "differences-in-differences" estimates of the local average treatment effects of the productivity shock. In particular, we construct a regression sample including both treated and untreated counties from our 3,111 counterfactuals in which we shock each 
county in turn with a 5 percent productivity shock $\left(3,111^{2}=9,678,321\right.$ observations). We use these data to estimate a "differences-in-differences" specification of a similar form to (29):

$$
\Delta \ln Y_{i t}=a_{0}+a_{1} \mathbb{I}_{i t}+a_{2} X_{i t}+a_{3}\left(\mathbb{I}_{i t} \times X_{i t}\right)+u_{i t}
$$

where $i$ denotes the 3,111 counties and $t$ indexes the 3,111 counterfactuals; $\Delta \ln Y_{i t}$ is the change in log employment between the counterfactual and actual equilibria; $\mathbb{I}_{i t}$ is a $(0,1)$ indicator for whether a county is treated with a productivity shock; and $X_{i t}$ are controls. We again consider two sets of controls $\left(X_{i t}\right)$ : the model-suggested measures of linkages in goods and factor markets and more standard econometric controls (log employment, log wages and land area). We include both the main effects of these controls (captured by $a_{2}$ ) and their interactions with the treatment indicator to capture heterogeneity in the treatment effects (captured by $a_{3}$ ).

A key difference between this regression specification and the above results for the general equilibrium elasticities for the treated counties is that this regression specification differences relative to the untreated counties. The empirical literature has argued for the need to difference relative to untreated counties given the likely presence of other shocks or events, beyond the treatment, that can affect the treated counties simultaneously and can confound the true treatment effect. Of course, our synthetic dataset was generated without including any of these alternative shocks and so differencing is not needed in order to calculate the correct treatment effects.

In a specification without the controls $\left(a_{2}=a_{3}=0\right)$, the average effect of the productivity shock on the untreated counties is captured in the regression constant $\left(a_{0}\right)$, and the local average treatment effect $\left(a_{1}\right)$ corresponds to the difference in means between the treated and untreated counties. We compare estimating this regression specification including (i) a random untreated county in the control group, (ii) only the nearest untreated county in the control group, (iii) only neighboring counties within 120 kilometers of the treated county in the control group, (iv) only non-neighboring counties located from 120-240 kilometers from the treated county, and (v) all untreated counties in the control group.

We compare the predicted treatment effect from the "differences-in-differences" specification to the general equilibrium employment elasticity in the model by computing the following deviation term for the treated county:

$$
\beta_{i}=\frac{a_{1}+a_{3} X_{i t}}{0.05}-\frac{d L_{i}}{d A_{i}} \frac{A_{i}}{L_{i}}
$$

which corresponds to the difference between the predicted treatment effect, scaled by the size of the productivity shock, and the general equilibrium employment elasticity in the model. In Figure 6 we show kernel densities of the distribution of this deviation term across the 3,111 counterfactuals for productivity shocks to each county. We show the deviation term using model-suggested controls (solid lines) and reduced-form controls (dashed lines). We display these results for each of the alternative control groups considered above ((i) to (v)). 
"Closest" and "All Obs." Controls

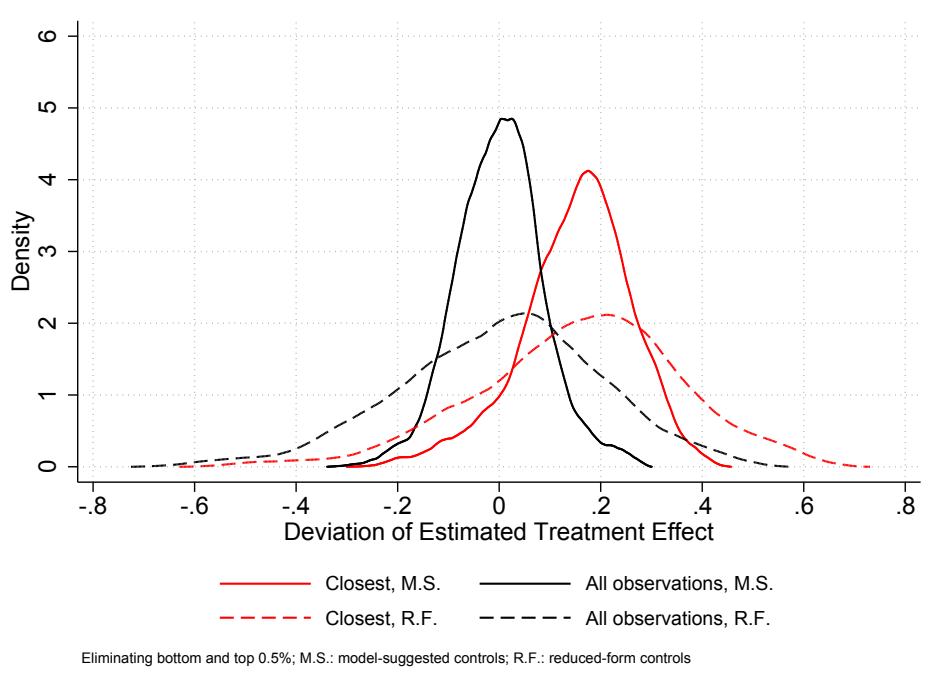

All Other Controls

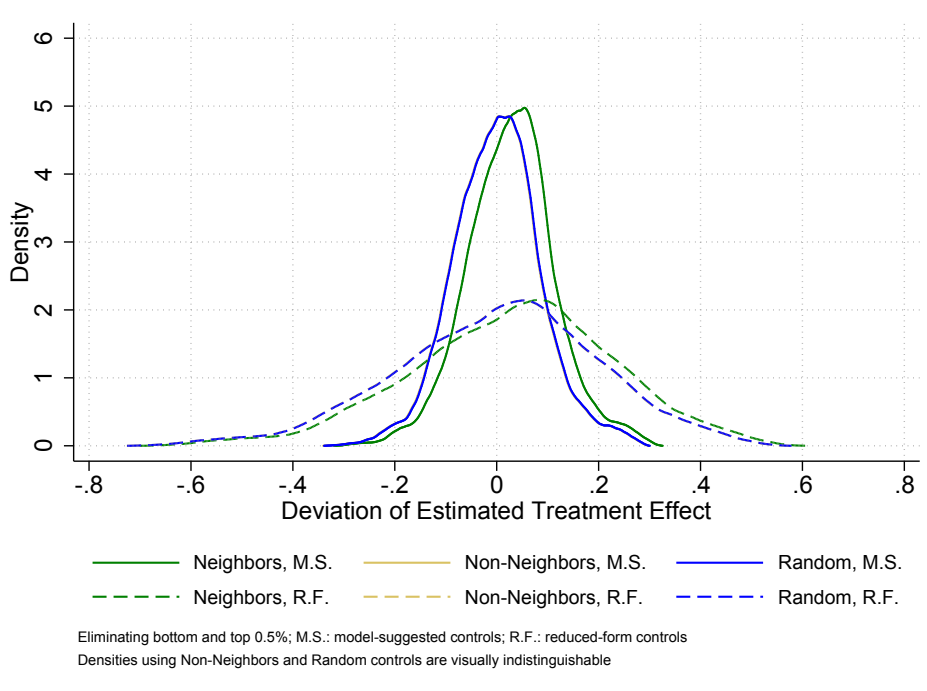

Figure 6: Distribution of the deviation term $\beta_{i}$ across counties $i$, for different estimations

As shown in the figure, none of the "differences-in-differences" specifications completely captures the general equilibrium employment elasticity, as reflected in the substantial mass away from zero in these distributions. However, taking into account commuting linkages with the model-suggested controls substantially increases the predictive power of the "differences-in-differences" specification, as shown by substantial reduction in the mass away from zero using model-suggested rather than reduced-form controls. In general, we find similar results across the different control groups, with the results using random counties ((i) above) and non-neighbors ((iv) above) visually indistinguishable in the right-hand panel. However, we find a substantially larger deviation term using the nearest county as a control, because employment in the nearest untreated county is typically negatively affected by the increase in productivity in the treated county. While the use of contiguous locations as controls is often motivated based on similar unobservables (as in regression discontinuity designs), this pattern of results highlights that contiguous locations are also likely to be the most severely affected by spatial equilibrium linkages in goods and factor markets.

In Subsection C.5 of the web appendix, we provide further evidence that the model-suggested controls are more successful in explaining the heterogeneity in treatment effects than the standard controls. In Subsection C.6 of the web appendix, we show that we find a similar pattern of results if we use spatially correlated shocks reproducing the industrial composition of the U.S. economy, and in Subsection C.10 of the web appendix, we show that we obtain the same pattern of findings if we replicate our entire quantitative analysis using CZs rather than counties. Therefore, while capturing the full general equilibrium effects of the productivity shocks requires solving the model-based counterfactuals, we find that augmenting "difference-in-difference" regressions with measures of commuting linkages substantially improves their ability to predict the heterogeneity in the estimated treatment effects. 


\subsection{Million Dollar Plants Natural Experiment}

Having established the heterogeneity of local employment elasticities in our quantitative model, due to differences in commuting linkages across counties, we now use evidence from a natural experiment to provide independent verification of this prediction in the data. In particular, we use the natural experiment of million dollar plants (MDP) from GHM (2010), one of the most influential papers in the local labor markets literature. The identification strategy compares employment in "winning" and "runner-up" counties before and after the opening of a MDP. As the runner-up counties are those that survived a long selection process, but narrowly lost the competition to winning counties, one would expect the two groups to have similar initial characteristics. Consistent with this, GHM show that winning and runner-up counties are similar along a range of observables before a MDP opening. In contrast, GHM show that the two groups exhibit sharply different trajectories following a MDP opening: winning counties experience larger plantlevel increases in total factor productivity (TFP), and have larger county-level increases in the number of manufacturing plants and total manufacturing employment and output.

For our empirical analysis, we start with a list of 82 MDP announcements ("cases") containing winner and runner-up counties from the corporate real estate journal Site Selection, as reported in Greenstone and Moretti (2004). Only a subset of 47 of these MDP announcements could be located in confidential census data by GHM (2010), in part because not all of the announced plants were necessarily ultimately opened. To be conservative (and because the census data are confidential), we use the full list of 82 announcements, where the fact that some of these plants may not have actually opened (or may have opened some time after the announcement date) will make it harder for us to find discernible effects. We begin by estimating the average treatment effect of a MDP announcement. Consistent with the reduced-form specification from the previous subsection, we estimate a "differences-in-differences" regression, where the first difference is before and after the announcement, and the second difference is between winning and runner-up counties. For each year $\tau>0$ after the announcement of a MDP, we difference log county employment relative to its value in the year of the announcement $(\tau=0)$ and estimate a specification given by

$$
\Delta \ln Y_{i k \tau}=\alpha_{\tau} \mathbb{I}_{i k \tau}+\mu_{k \tau}+u_{i k \tau}
$$

where $i$ again indexes counties and $k$ denotes cases (instances of winner and runner-up counties); we estimate this regression separately for each year $\tau>0 ; \Delta \ln Y_{i k \tau}$ is the change in log employment between the announcement and year $\tau$; the first differencing over time has eliminated any county fixed effect in the level of $\log$ employment; $\mathbb{I}_{i k \tau}$ is a treatment indicator that equals one if a county $i$ for case $k$ has an announced MDP in year $\tau$ and zero otherwise; $\mu_{k \tau}$ is a case fixed effect that captures average employment growth up to year $\tau$ for both the winner and runner-up counties in case $k ; \alpha_{\tau}$ is the key coefficient of interest and corresponds to the average treatment effect of a MDP announcement.

We next examine the extent to which the treatment effect of a MDP announcement is heterogeneous

across counties depending on their commuting linkages, as predicted by our quantitative model. Motivated by the results of our counterfactuals in the previous section, we measure these commuting linkages using 
each county's own commuting share. We augment the "differences-in-differences" regression in (31) with both the main effect of the own commuting share $\left(\lambda_{i i \mid i}\right)$ and the interaction term between the MDP announcement and the own commuting share $\left(\lambda_{i i \mid i} \times \mathbb{I}_{i k \tau}\right)$. So we estimate

$$
\Delta \ln Y_{i k \tau}=\alpha_{\tau} \mathbb{I}_{i k \tau}+\beta_{\tau} \lambda_{i i \mid i}+\gamma_{\tau}\left(\lambda_{i i \mid i} \times \mathbb{I}_{i k \tau}\right)+\mu_{k \tau}+u_{i k \tau}
$$

where the coefficient $\beta_{\tau}$ on the main effect allows for the possibility that counties open versus closed to commuting could differ in employment growth for other reasons besides the MDP announcement; the key coefficient of interest is $\gamma_{\tau}$ on the interaction term, which captures heterogeneity in the response of local employment to the MDP announcement. Based on our quantitative model, we expect $\gamma_{\tau}$ to be negative and statistically statistically significant, such that counties more closed to commuting (higher own commuting shares $\lambda_{i i \mid i}$ ) have smaller local employment responses.

In Table 3, we report the estimation results. To provide a point of comparison, Panel A estimates equation (31) including only the case fixed effects (without the treatment indicator). Across periods ranging up to five years after the MDP announcement, we find that the case fixed effects alone explain around 18 to 29 percent of the variance in county employment growth. In Panel B, we estimate the average treatment effect of the MDP announcement using our baseline specification (31) (including the treatment indicator). We find strong confirmation of the empirical results in GHM (2010), with a positive and statistically significant average treatment effect. The magnitude of this treatment effect is substantial, ranging from 2.6 percent to more than 6 percent as we move from one to five years after the announcement. We also find that the MDP announcement has substantial explanatory power for county employment growth, with the regression R-squared rising to a range of 27 to 29 percent.

In Panel C, we estimate heterogeneous treatment effects using our augmented specification (32) (including the own commuting share terms). Confirming our model's predictions, the estimated coefficient on the interaction term $\left(\gamma_{\tau}\right)$ is negative and statistically significant, implying that the MDP announcement has smaller employment effects in counties more closed to commuting. The implied magnitude of this heterogeneity is large compared to the average treatment effect of 2 to 6 percent from Panel B. For a county with an own commuting share at the 75th percentile the predicted employment effect is between 23.6 and 26.6 percent (depending on the number of years after the treatment) smaller than for a county with a commuting share at the 25 th percentile. In fact, in our quantitative model, the same exercise using simulated data yields a slightly smaller reduction in the predicted employment effect (18.2 percent). If we compare the 90th and 10th percentile of own commuting shares the difference in employment effects ranges between $49 \%$ and $43 \%$ (again depending on the number of years after treatment). In our quantitative model, the same difference is $31.7 \%$. We conclude that the impact of commuting linkages on the employment response to the MDP is statistically significant and large in economic terms. The reductions in the employment effect of the treatment that result from higher own commuting shares are of the same magnitude, but somewhat larger, than the ones predicted by our quantitative model. So, if anything, our model seems to underplay the importance of commuting compared to the data. 


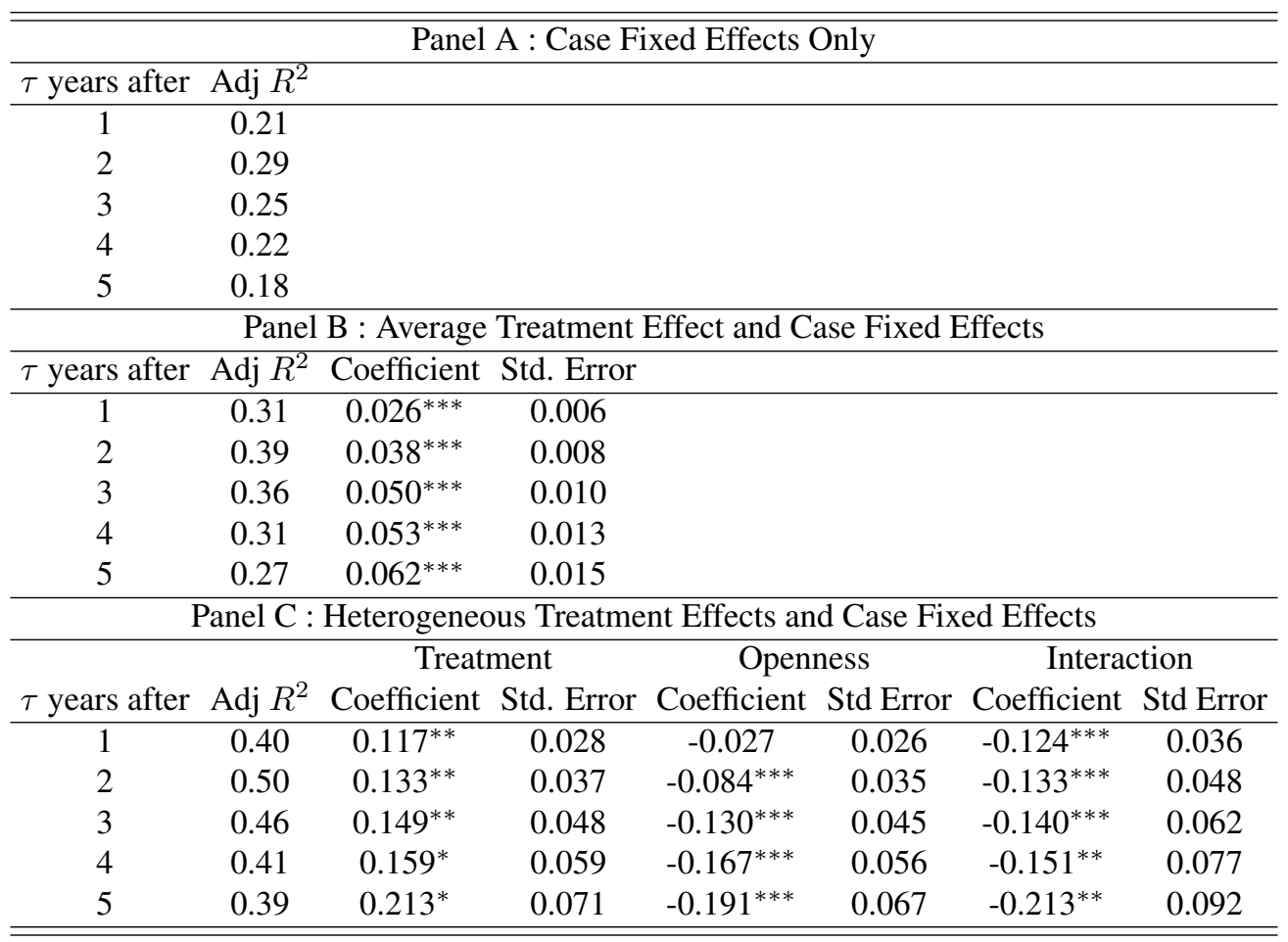

This table reports estimates of versions of equations (31) and (32). Case fixed effects are never reported. Panel A estimates equation (31) including only the case fixed effects $\mu_{k \tau}$ (i.e. without the treatment indicator $\mathbb{I}_{i k \tau}$ ). Panel B estimates the average treatment effect of the MDP announcement using specification (31). Panel C estimates heterogeneous treatment effects using specification (32). In Panel C, "Treatment" refers to the coefficient $\alpha_{\tau}$, "Openness" refers to the coefficient $\beta_{\tau}$, and "Interaction" refers to the coefficient $\gamma_{\tau}$ as in equation (32). * $p<0.1 ; * * p<0.05$; *** $p<0.01$.

Table 3: Million Dollar Plants Natural Experiment

We also find a negative and statistically significant main effect $\left(\beta_{\tau}\right)$ of the own commuting share, consistent with counties that are more closed to commuting growing more slowly on average. Comparing Panels C and B, allowing for heterogeneous treatment effects leads to a substantial further increase in the regression R-squared to 40-50 percent. Therefore the increase in explanatory power from allowing for treatment heterogeneity depending on commuting links is around as large as that from allowing for average treatment effects (Panels A-B).

Finally, the results in Table 3 also indicate that the average treatment effects estimated by GHM (2010) depend on the average amount of commuting in the economy at the time of the treatment. An economy with larger average own commuting shares generates smaller average treatment effects than an economy with smaller own commuting shares. This elasticity is governed by $\gamma_{\tau}$, which is highly significant and increases in absolute magnitude (declines from -0.124 to -0.213 ) over the first five years after treatment.

Taking the results of this section together, using the natural experiment of million dollar plants (MDP) as an independent source of variation, we find strong confirmation of our model's prediction of heterogeneous local employment elasticities depending on commuting networks. Comparing counties that are otherwise similar, except for whether they were ultimately fortunate enough to attract a MDP, we find substantially larger increases in employment in winner counties than in runner-up counties, and this increase 
in employment is considerably greater for those winner counties that are more open to commuting.

\section{Changes in Commuting Costs}

In the previous sections, we have shown the importance of commuting for the effects of local labor demand shocks. We now show that it also matters in the aggregate for the spatial distribution of economic activity across locations and welfare. Commuting enables workers to access high productivity locations without having to pay the high cost of living in those locations. Increasing the cost of commuting restricts the opportunity set available to firms and workers and hence is expected to reduce welfare. Locations that were previously net exporters of commuters in the initial equilibrium become less attractive residences, while locations that were previously net importers of commuters in the initial equilibrium become less attractive workplaces. As agents relocate in response to the restricted opportunity set, we also expect a decline in the specialization of counties as residential or business locations.

We begin by using the observed commuting data to back out implied values of the composite parameter capturing the ease of commuting $\left(\mathcal{B}_{n i} \equiv B_{n i} \kappa_{n i}^{-\epsilon}\right)$. Following Head and Ries (2001) in the international trade literature, we use the flows of commuters between locations $n$ and $i$ in both directions relative to their own commuting flows. Using the commuting gravity equation (11), and taking the geometric mean of these relative flows in both directions, we obtain the following measure of the average ease of commuting between locations $n$ and $i$ relative to the ease of commuting to themselves:

$$
\tilde{\mathcal{B}}_{n i} \equiv\left(\frac{\mathcal{B}_{n i}}{\mathcal{B}_{n n}} \frac{\mathcal{B}_{i n}}{\mathcal{B}_{i i}}\right)^{1 / 2}=\left(\frac{L_{n i}}{L_{n n}} \frac{L_{i n}}{L_{i i}}\right)^{1 / 2}
$$

We compute this measure for both 1990 and 2010. Between these two years, both miles of paved roads and vehicle kilometers travelled increased substantially. ${ }^{34}$ Consistent with this, we find a substantial increase in the relative ease of commuting from 4 percent $\left(\hat{\tilde{\mathcal{B}}}_{n i}=0.96\right)$ at the 25 th percentile, to 12 percent $\left(\hat{\tilde{\mathcal{B}}}_{n i}=0.88\right)$ at the median, and 21 percent $\left(\hat{\tilde{\mathcal{B}}}_{n i}=0.79\right)$ at the 75 th percentile.

We use this distribution of implied changes in the relative ease of commuting to undertake counterfactuals for empirically-realistic changes in commuting costs. We assume a common reduction or increase in the costs of commuting for all counties equal to percentiles of this distribution (e.g. we assume that all counties experience a reduction in commuting costs equal to the median value of $\hat{\tilde{\mathcal{B}}}_{n i}$ ). Given this assumption, we use the system of equations for general equilibrium in the model to solve for the new counterfactual equilibrium after the reduction in commuting costs, as discussed in Section 2.6 above. Using the commuting probability (11), expected utility (16), the price index (9) and land market clearing (5), the change in the common level of welfare across all locations from the shock to commuting costs can be

\footnotetext{
${ }^{34}$ Between 1990 and 2010, kilometers of paved public roads in the United States increased by over 20 percent (from 3.6 to 4.4 million), and vehicle kilometers travelled increased by more than 38 percent (from 3,451,016 to 4,775,352 million). For further discussion of this expansion in transport use, see for example Duranton and Turner (2011).
} 
decomposed as follows:

$$
\widehat{\bar{U}}=\left(\frac{1}{\widehat{\lambda}_{i i}}\right)^{\frac{1}{\epsilon}}\left(\frac{1}{\widehat{\pi}_{i i}}\right)^{\frac{\alpha}{\sigma-1}}\left(\frac{\widehat{w}_{i}}{\widehat{\bar{v}}_{i}}\right)^{1-\alpha} \frac{\widehat{L}_{i}^{\frac{\alpha}{\sigma-1}}}{\hat{R}_{i}^{1-\alpha}}
$$

where we have used the fact that $\left\{\kappa_{i i}, B_{i i}, A_{i}, d_{i i}\right\}$ are unchanged; the first term in $\widehat{\lambda}_{i i}$ captures the impact through changes in openness to commuting; the second term in $\widehat{\pi}_{i i}$ captures the effect through adjustments in openness to goods trade; the remaining terms capture the influence of changes in the spatial distribution of wages $\left(\widehat{w}_{i}\right)$, expected residential income $\left(\bar{v}_{i}\right)$, employment $\left(\widehat{L}_{i}\right)$ and residents $\left(\hat{R}_{i}\right)$.

\begin{tabular}{|c|c|c|c|c|}
\hline & Decrease by p75 & Decrease by p50 & Decrease by p25 & Increase by $1 / \mathrm{p} 50$ \\
\hline Implied $\tilde{\tilde{\mathcal{B}}}_{n i}$ & 0.79 & 0.88 & 0.96 & 1.13 \\
\hline Welfare Change & $6.89 \%$ & $3.26 \%$ & $0.89 \%$ & $-2.33 \%$ \\
\hline
\end{tabular}

This table shows the percentage change in welfare for different counterfactual changes in commuting costs. Each column reports a different counterfactual exercise; p75, p50 and p25, respectively, are the 75th, 50th and 25th percentiles of the empirical distribution of changes in the ease of commuting $\hat{\tilde{\mathcal{B}}}_{n i}$ from 1990-2010. The first row reports the implied $\hat{\tilde{\mathcal{B}}}_{n i}$ for all counties. The second row reports the percentage change in welfare for each counterfactual.

Table 4: Welfare Impacts for different Changes in Commuting Costs

As shown in Table 4, we find substantial effects of the reductions in commuting costs on aggregate welfare. Reducing commuting costs by the median proportional change observed over our time period from 1990 to 2010 is predicted to increase welfare by around 3.3 percent (second column). In contrast, raising commuting costs by the same proportional amount decreases welfare by around 2.3 percent. As we scale up the reduction in commuting costs to the 75 th percentile observed over our time period, we amplify the welfare gain to 6.9 percent (first column). As we scale down the reduction in commuting costs to the 25th percentile, we diminish the welfare gain to 0.89 percent (third column). These proportional changes in welfare from empirically-realistic changes in commuting costs are large relative to standard empirical estimates of the welfare gains from opening the closed economy to international trade, which for example range from less than 1 percent for the United States to just over 10 percent for Belgium in Eaton and Kortum (2002). While commuting flows typically occur at much smaller spatial scales than international trade flows, these results clearly highlight that commuting not only shapes the impact of local shocks but is also consequential for aggregate welfare. ${ }^{35}$

These empirically-realistic changes in commuting costs also result in substantial changes in the spatial distribution of employment and residents across locations. In Figure 7, we show the counterfactual change in employment in each county from reducing commuting costs by the median proportional change observed over our time period from 1990 to 2010. We display these counterfactual changes in employment

\footnotetext{
${ }^{35}$ Smaller (larger) values for the Fréchet shape parameter $(\epsilon)$ imply more (less) heterogeneity in preferences for residenceworkplace pairs, which magnifies (diminishes) the effects of changes in commuting costs on welfare. For example, in a world with a 50 percent lower (higher) value of $\epsilon$, reducing commuting costs by the median proportional change increases welfare by 6.9 (2.1) percent, while increasing commuting costs by the same amount reduces welfare by 4.8 (1.5) percent.
} 


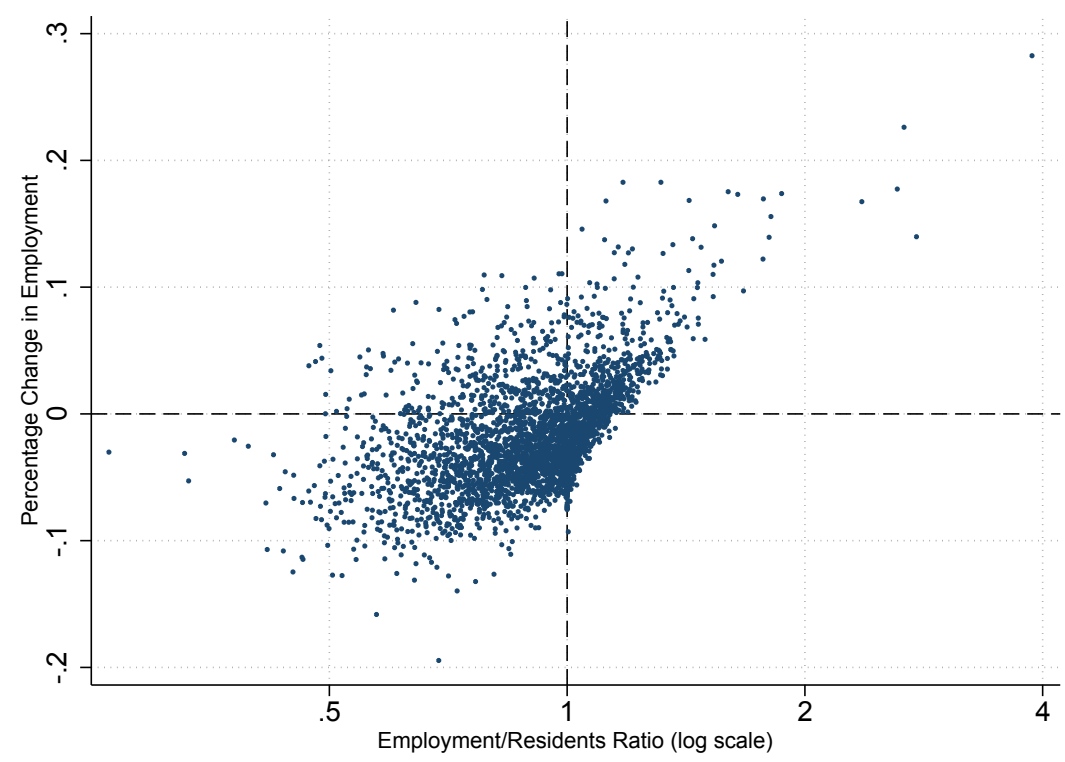

Figure 7: Counterfactual relative change in county employment $(\hat{L})$ for median decrease in commuting costs throughout U.S. against initial employment to residents ratio $(L / R)$.

against each county's initial commuting intensity $L_{i} / R_{i}$, where $L_{i} / R_{i}>1$ implies that a county is a net importer of commuters and $L_{i} / R_{i}<1$ implies that a county is a net exporter of commuters. We find substantial changes in employment for individual counties, which range from increases of 28 percent to reductions of 19 percent, and are well explained by initial commuting intensity. As discussed in Subsection 3.2 above and shown in Subsection C.1 of the web appendix, initial commuting intensity is itself hard to explain in terms of standard empirical controls, such as land area, size and housing supply elasticities, and hence cannot easily be proxied by these variables.

In Subsection C.10 of the web appendix, we provide further evidence that the importance of commuting is by no means restricted to large cities. We undertake counterfactuals for reductions in commuting costs for $\mathrm{CZs}$ rather than counties (replicating our entire quantitative analysis for $\mathrm{CZs}$ ). We show that the counterfactual changes in $\mathrm{CZ}$ employment from reductions in commuting costs are well explained by measures of the extent to which the $\mathrm{CZ}$ uses the commuting technology in the initial equilibrium. In contrast, these counterfactual changes in CZ employment are not well explained by initial CZ employment or residents size, confirming the importance of measures of commuting linkages.

Given this importance of commuting links in shaping the distribution of economic activity across locations, it is natural to expect that these links also determine the magnitude of the impact of reductions in trade costs. In Subsection C.9 of the web appendix, we explore this interaction between trade and commuting costs. We compare the counterfactual effects of a 20 percent reduction of trade costs in the actual world with commuting to the effects in a hypothetical world without commuting. In general, reductions in trade costs lead to a more dispersed spatial distribution of economic activity in the model. But this dispersal is smaller with commuting than without commuting. As trade costs fall, commuting increases the ability of the most productive locations to serve the national market by drawing workers from a suburban hinterland, without bidding up land prices as much as would otherwise occur. These results further under- 
score the prominence of commuting linkages in shaping the equilibrium spatial distribution of economic activity, and the necessity of incorporating them in models of economic geography.

\section{Conclusions}

The economic effects of local labor demand shocks have been the subject of an extensive empirical literature on local labor markets, which has considered a wide range of such shocks, including industry composition, international trade, macro and financial crises, and natural resource discoveries, among others. To understand the impact of these types of shocks, we develop a quantitative spatial general equilibrium model that incorporates spatial linkages between locations in both goods markets (trade) and factor markets (commuting and migration). Although we allow for a large number of locations and a rich geography in both goods and factor markets, we provide analytical results for the existence and uniqueness of the general equilibrium. We show how the model can be quantified using available data to match the observed gravity equation relationships for trade in goods and commuting, as well as the observed cross-section distributions of employment, residents and wages. Thus, our framework provides a tractable platform for undertaking a range of counterfactuals for realistic changes in trade and commuting costs.

Whereas previous research has largely treated local labor markets as independent observations in crosssection regressions, we explicitly model the spatial linkages between these locations, which enables us to undertake our analysis at different levels of spatial aggregation. Through modeling these linkages, we overcome a trade-off faced in existing research, namely that choosing larger spatial units reduces unmodeled spatial linkages between locations, but also reduces the ability to make inferences about local labor markets. We show that commuting flows are substantial and heterogeneous across both counties and commuting zones $(\mathrm{CZs})$ in the United States. Although the boundaries of CZs are chosen to minimize commuting, no choice of boundaries is able to fully capture the rich geography of commuting flows implied by the gravity equation.

Commuting allows workers to separate their workplace and residence, thereby introducing a quantitatively relevant distinction between the effects of local labor demand shocks on employment and residents. We find substantial heterogeneity across both counties and CZs in the elasticity of local employment to a productivity shock, which ranges from around 0.5 to 2.5 . Therefore an average local employment elasticity estimated in one context can be quite misleading if applied in another context without controlling for this heterogeneity. We show that this heterogeneity is hard to explain with standard empirical controls, such as area and size, but is well explained by measures of linkages in commuting networks. We use our model to highlight a simple summary statistic of the share of residents that work locally that can be included in reduced-form regressions to control for this heterogeneity.

We show that our finding of heterogeneous local employment elasticities is robust across a wide range of different specifications, including the introduction of differences in supply elasticities for developed land. These findings are consistent with such heterogeneity being a generic prediction of a commuting gravity equation, which is a strong empirical feature of the data. We also use the natural experiment of 
million dollar plants (MDPs) to provide further independent empirical support for our model's predictions. We compare counties that are otherwise similar, except for whether they were ultimately fortunate enough to attract a MDP. We find substantially larger increases in employment in winner counties than in runner-up counties, and this increase in employment is considerably greater for those winner counties more open to commuting. Finally, as well as shaping the effects of local labor demand shocks, we show that commuting also matters in the aggregate for the spatial distribution of economic activity and welfare. We use observed commuting flows between pairs of counties over time to back out the empirical distribution of implied reductions in commuting costs from 1990-2010. Reducing commuting costs for all counties by the median of this empirical distribution, we find an increase in welfare of 3.3 percent, and employment changes across counties that range from increases of 28 percent to reductions of 19 percent.

The quantitative model we propose is, we believe, ambitious and rich, yet its core insights are also relatively general. So we hope that our results are used to motivate the inclusion of measures of commuting in future estimation of local employment elasticities. Their inclusion is simple, practical, and well grounded in theory.

\section{References}

[1] Ahlfeldt, Gabriel, Stephen Redding, Daniel Sturm and Nikolaus Wolf (2015) "The Economics of Density: Evidence from the Berlin Wall," Econometrica, 83(6), 2127-2189.

[2] Allen, Treb, and Costas Arkolakis (2014) “Trade and the Topography of the Spatial Economy," Quarterly Journal of Economics, 129(3), 1085-1140.

[3] Allen, Treb, Costas Arkolakis and Yuta Takahashi (2014) "Universal Gravity," NBER Working Paper, 20787.

[4] Allen, Treb, Costas Arkolakis and Xiangliang Li (2015) “Optimal City Structure,” Yale University, mimeograph.

[5] Alonso, William (1964) Location and Land Use, Cambridge MA: Harvard.

[6] Arkolakis, Costas, Arnaud Costinot and Andres Rodriguez-Clare (2012) "New Trade Models, Same Old Gains," American Economic Review, 102(1), 94-130.

[7] Armington, Paul S. (1969) "A Theory of Demand for Products Distinguished by Place of Production," IMF Staff Papers, 16(1), 159-178.

[8] Artuc, E., S. Chaudhuri, and J. McLaren (2010) "Trade Shocks and Labor Adjustment: A Structural Empirical Approach,” American Economic Review, 100(3), 1008-1045.

[9] Autor David, David Dorn and Gordon Hanson (2013) “The China Syndrome: Local Labor Market Effects of Import Competition in the United States," American Economic Review, 103(6), 2121-2168.

[10] Bartik, Timothy J. (1991) "Who Benefits from State and Local Economic Development Policies?" W.E. Upjohn Institute for Employment Research, Upjohn Press. 
[11] Behrens, K., G. Mion, Y. Murata and J. Südekum, 2014. "Spatial frictions," DICE Discussion Papers 160, Heinrich-Heine-Universität Düsseldorf, Düsseldorf Institute for Competition Economics (DICE).

[12] Blanchard, Olivier Jean, and Lawrence F. Katz (1992) "Regional Evolutions," Brookings Papers on Economic Activity, 23(1), 1-76.

[13] Bound, John and Holzer, Harry J (2000) "Demand Shifts, Population Adjustments, and Labor Market Outcomes during the 1980s," Journal of Labor Economics, 18(1), 20-54.

[14] Broda, Christian and David E. Weinstein (2006) "Globalization and the Gains from Variety," Quarterly Journal of Economics, 121(2), 541-86.

[15] Busso, M., J. Gregory, and P. Kline (2013) "Assessing the Incidence and Efficiency of a Prominent Place Based Policy," American Economic Review, 103(2), 897-947.

[16] Caliendo, L. and F. Parro (2015) "Estimates of the Trade and Welfare Effects of NAFTA," Review of Economic Studies, 82(1), 1-44.

[17] Caliendo, L., F. Parro, E. Rossi-Hansberg, and P.-D. Sarte (2014) “The Impact of Regional and Sectoral Productivity Changes on the U.S. Economy," NBER Working Paper, 20168.

[18] Dekle, R., J. Eaton, and S. Kortum (2007) “Unbalanced Trade,” American Economic Review, 97(2), 351-355.

[19] Desmet, Klaus and Esteban Rossi-Hansberg (2013) “Urban Accounting and Welfare,” American Economic Review, 103:6, 2296-2327.

[20] Desmet, Klaus and Esteban Rossi-Hansberg (2014) "Spatial Development," American Economic Review, 104(4), 1211-1243.

[21] Diamond, Rebecca (2016) "The Determinants and Welfare Implications of US Workers? Diverging Location Choices by Skill: 1980-2000,” American Economic Review, 106(3), 479-524.

[22] Dingel, Jonathan (2015) “The Determinants of Quality Specialization," Chicago Booth School of Business, mimeograph.

[23] Duranton, Gilles and Matthew A. Turner (2011) “The Fundamental Law of Road Congestion: Evidence from U.S. Cities,” American Economic Review, 101(6), 2616-2652.

[24] Duranton, Gilles, Peter Morrow and Matthew A. Turner (2014) "Roads and Trade: Evidence from the U.S.," Review of Economic Studies, 81(2), 681-724.

[25] Eaton, Jonathan and Kortum, Samuel (2002) “Technology, Geography, and Trade,” Econometrica, 70(5), 1741-1779.

[26] Feyrer, James, Erin T. Mansur and Bruce Sacerdote (2015) "Geographic dispersion of economic shocks: Evidence from the fracking revolution" NBER Working Paper, 21624.

[27] Fujita, Masahisa, Paul Krugman and Anthony J. Venables (1999) The Spatial Economy: Cities, Regions and International Trade, Cambridge: MIT Press. 
[28] Greenstone, M. and E. Moretti (2004) “Bidding for Industrial Plants: Does Winning a 'Million Dollar Plant' Increase Welfare?" NBER Working Paper, 9844.

[29] Greenstone, M., R. Hornbeck, and E. Moretti (2010) "Identifying Agglomeration Spillovers: Evidence from Winners and Losers of Large Plant Openings," Journal of Political Economy, 118(3), 536-598.

[30] Grogger, J., and G. Hanson (2011) "Income Maximization and the Selection and Sorting of International Migrants," Journal of Development Economics, 95(1), 42-57.

[31] Hanson, G. H. (1996) “Localization Economies, Vertical Organization, and Trade," American Economic Review, 86(5), 1266-1278.

[32] Hanson, Gordon H. (2005) "Market Potential, Increasing Returns, and Geographic Concentration," Journal of International Economics, 67(1), 1-24.

[33] Head, Keith and John Ries (2001) "Increasing Returns versus National Product Differentiation," American Economic Review, 91, 858-876.

[34] Helpman, Elhanan (1998) "The Size of Regions," In Topics in Public Economics: Theoretical and Applied Analysis, ed. David Pines, Efraim Sadka, and Itzhak Zilcha, Cambridge: Cambridge University Press.

[35] Kennan, J., and J. R. Walker (2011) “The Effect of Expected Income on Individual Migration Decisions," Econometrica, 79(1), 211-251.

[36] Krugman, Paul (1991) “Increasing Returns and Economic Geography,” Journal of Political Economy, 99(3), 483-99.

[37] Krugman, Paul and Anthony J. Venables (1995) “Globalization and the Inequality of Nations," Quarterly Journal of Economics, 110(4), 857-880.

[38] Lucas, Robert E. and Esteban Rossi-Hansberg (2002) “On the Internal Structure of Cities”, Econometrica, 70(4), 1445-76.

[39] Manning, Alan and Barbara Petrongolo (2011) "How Local are Labour Markets? Evidence from a Spatial Search Model”, CEP Discussion Paper, No. 1101, London School of Economics.

[40] McFadden, D. (1974) “The Measurement of Urban Travel Demand," Journal of Public Economics, 3(4), 303-328.

[41] McFadden, Daniel and Kenneth Train (2000) "Mixed MNL Models of Discrete Response," Journal of Applied Econometrics, 15, 447-470.

[42] Melitz, Marc J. (2003) “The Impact of Trade on Intra-Industry Reallocations and Aggregate Industry Productivity," Econometrica, 71(6), 1695-1725.

[43] Mian, Atif and Amir Sufi (2014) “What Explains the 2007-2009 Drop in Employment?" Econometrica, 82(6), 2197-2223.

[44] Michaels, Guy (2011) “The Long Term Consequences of Resource-Based Specialisation,” Economic Journal, 121(551), 31-57. 
[45] Mills, Edwin S. (1967) "An Aggregative Model of Resource Allocation in a Metropolitan Centre," American Economic Review, 57(2), 197-210.

[46] Monte, Ferdinando (2016) “The Local Incidence of Trade Shocks,” Georgetown University, mimeograph.

[47] Moretti, Enrico (2011) “Local Labor Markets," in Handbook of Labor Economics, (ed.) D. Card, and O. Ashenfelter, Volume 4b, Amsterdam: Elsevier North Holland, 1238-1303.

[48] Moretti, Enrico and Patrick Klein (2011) "Local Economic Development, Agglomeration Economies, and the Big Push: 100 Years of Evidence from the Tennessee Valley Authority," Quarterly Journal of Economics, 129(1), 275-331.

[49] Muth, Richard (1969) Cities and Housing, Chicago: University of Chicago Press.

[50] Notowidigdo, Matthew (2013) “The Incidence of Local Labor Demand Shocks," Northwestern University, mimeograph.

[51] Rappaport, Jordan and Jeffrey D. Sachs (2003) "The United States as a Coastal Nation", Journal of Economic Growth, 8(1), 5-46.

[52] Redding, Stephen J. and Daniel Sturm (2008) "The Costs of Remoteness: Evidence from German Division and Reunification,” American Economic Review, 98(5), 1766-1797.

[53] Redding, Stephen J. and Matthew Turner (2015) "Transportation Costs and the Spatial Organization of Economic Activity," in (eds) Gilles Duranton, J. Vernon Henderson and William Strange, Handbook of Urban and Regional Economics, Chapter 20, 1339-1398.

[54] Redding, Stephen J. (2016) “Goods Trade, Factor Mobility and Welfare,” Journal of International Economics, 101, 148-167.

[55] Rossi-Hansberg, Esteban (2005) “A Spatial Theory of Trade,” American Economic Review, 95(5), 1464-1491.

[56] Saiz, Albert (2010) “The Geographic Determinants of Housing Supply,” Quarterly Journal of Economics, 125(3), 1253-1296.

[57] Simonovska, Ina and Michael E. Waugh (2014) “The Elasticity of Trade: Estimates and Evidence," Journal of International Economics, 92(1), 34-50.

[58] Tolbert, Charles M. and Molly Sizer (1996) "U.S. Commuting Zones and Labor Market Areas: a 1990 Update," U.S. Department of Agriculture Staff Paper, AGES-9614.

[59] United States Department of Justice, Federal Bureau of Investigation. (September 2008). Crime in the United States, 2007. Retrieved 10/15/2016, from https://www2.fbi.gov/ucr/cius2007/.

[60] Yagan, Danny (2016) "Moving to Opportunity? Migratory Insurance over the Great Recession," University of California, Berkeley. 